\title{
Gamifying the gig: transitioning the dark side to bright side of online engagement
}

\author{
Abhishek Behl \\ O.P. Jindal Global University, India \\ abhishekbehl27@gmail.com
}

\section{Pratima Sheorey}

SCM HRD, Symbiosis International (Deemed) University, Pune, India

\section{Kokil Jain}

Amity International Business School, Noida, India

\section{Meena Chavan}

Macquarie University Sydney Australia

\section{Isha Jajodia}

Birla Institute of Management Technology (BIM TECH), India

\section{Zuopeng (Justin) Zhang}

University of North Florida, USA

\section{Abstract}

Gig work has transformed the work culture, globally; its spread and popularity has attracted excellent talent, most of it online. While the gig sector has opened new avenues to showcase talent, lack of consistent engagement of gig workers have resulted in significant dropouts. The study addresses a key research gap by investigating digital platform gig work dropouts through the moderating impact of gamified interventions on online platforms. We have based our arguments and derived hypotheses on the basis of the social exchange theory and the selfdetermination theory. A total of 367 responses were collected from white-collar gig workers who had completed tasks on one or more gig platforms in the past two years. We test our hypotheses using partial least square structural equation modelling (PLS-SEM). Results confirm that gamifying the online platform would enhance job satisfaction and productivity of gig employees, thereby reducing their chances of quitting gig work. It is further observed that in the case of gig workers, high-performance work systems have a non-significant effect on the intentions to quit. The results contribute to the redesigning of online gig platforms with a layer of gamified artifacts to increase gig workers' retention.

Keywords: Gamification, Gig Work, Intention to Quit, Dark side, Engagement

\section{Introduction}

The changing nature of employment and a progressive shift in the working ecosystem that is fundamentally powered by the autonomous nature of the workforce has given rise to the "gig economy". Characterized by a free market system, conventional businesses in the "gig economy" engage independent freelancers on a short-term contract basis to perform tasks that they have expertise in. The term "gig" has been adopted from the context of performing artists who perform specific to an occasion or location - referred to as gig work (Longley, 2020). The Gig economy workers are paid as per tasks, unlike the typical salary-based pay-out in hierarchical organizations. This progressively evolving work structure signals a shift from the 
traditional career paths that made people work for firms as full-time employees to a more selfdriven alternative that empowers them to wisely choose gig work (Kurin, 2016).

With technologies disrupting standard working and employment practices, restructuring of business models and individuals aspiring for new and non-conventional career paths (Cooper, 2014; Davis, 2016) gig work appears to be an emerging and preferred pattern of work. It is reported that $36 \%$ of all U.S. workers were gig workers during 2018 and, $29 \%$ of all workers in the U.S. have an alternative work arrangement as their primary job. These figures indicate that about 57 million Americans had one or more gig jobs (McFeely \& Pendell, 2018). These prevailing trends have sought the attention of organizational researchers and practitioners, who are only beginning to explore the experiences of gig workers in coping with the complexities of this new employment structure (Caza, Moss, \& Vough, 2018; Petriglieri et al., 2018) and examining their motivation to engage in gig work (Jabagi et al., 2019).

Despite the growing popularity and demand for gig work among consumers, workers as well as employers, the gig economy sector is discussed as highly unregulated that poses a plethora of challenges (Kurin, 2016; Kuhn \& Galloway, 2019; Pichault \& McKeown, 201). Firms appear to be in a state of flux when they start involving gig in their routine work or a selection of occasional work. From the workers' perspective as well, there are significant concerns, as gig workers are largely contractual workers, who are not covered by the benefits given to full-time employees like health and retirement benefits, medical leaves, periodic increase in pay and job security. Additionally, there is an irregular and modest flow of income, high taxes, constant stress of looking for new gigs, etc. Recent studies have pointed out that this sector suffers from frequent dropouts by the workers, irregular patterns of work and lack of motivation that is often not contemplated by new entrants (Anwar \& Graham, 2020; Burtch et al., 2018). Many gig workers hold multiple jobs, like simultaneously or sequentially driving their cars for Uber, Ola, Lyft, Bolt, along with leasing out rooms in their homes through Airbnb. They also work on "digital earning platforms," like eBay, marketplace, and Etsy, by selling their used items and participating in online handyman services, like TaskRabbit.

While this provides them independence, flexibility of remote work and enables them to create a diverse career portfolio (Caza et al., 2018) it also inhibits their loyalty to a single organization or occupation (Ashford et al., 2018). Clearly, inhabiting different roles, juggling between different organizations and tasks is expected to have significant implications in terms of the worker's motivation. Ravenelle (2019) argue that despite digital platforms, marketing gig work as a form of entrepreneurship, gig-workers consider themselves as part-time employees and not entrepreneurs, which can affect their satisfaction and commitment towards the platform and the task. As an outcome of these issues, gig employers confront substantial challenges as they often report a mismatch between supply and demand due to a lack of available gig workforce (Healy et al., 2017). This may also lead to unhappiness of customers and loss of business. All these aspects together point towards the dark side of the gig economy which gives rise to some essential questions regarding the factors driving the motivation and retention of gig workers. Abraham et al., (2018) have argued that, even though the sector has large potential, its future largely depends on how we can control the irregularities in the operations of the gig work and keep the gig workers motivated and encourage their long term commitment.

Existing theories have long been used to explore employee motivation in traditional career structure and work settings. But this new form of employment has emphasized the need for 
scholars and practitioners to understand what accounts for individual motivation as they delve through constantly changing conditions in a gig economy (Ashford et al., 2018). It is not merely engagement with the online platform, but the continuous, uninterrupted nature of the engagement that is required to keep the business profitable (Behl, 2020). This unique context, where gig workers operate independently without any direct supervisors, necessitates the understanding of the process by which organizations can motivate gig-workers and support their well-being. Firms have practiced multiple ways like offering bonuses to gig workers during times of high demand, giving protection to the gig workers by offering life or workrelated insurance (Stewart \& Stanford, 2017) and, engaging them using lucrative schemes and offers (Prabowo et al., 2019). While such measures are mostly temporary (Jabagi et al., 2019), essential structural difference between conventional organizations and work in the gig economy calls for embedding the existing workflow with something that can help control the intrinsic and extrinsic motivation of the gig workers (Faisal et al., 2019).

Against this background, this study applies the concept of gamification in work-related tasks to explore and assess its role in controlling the gig workers' intentions to quit from the digital earning platforms. The growing research stream of work on gamification has extensively discussed its motivational and social benefits. Due to its potential to modify behavior, theorists and practitioners have begun to acknowledge the importance of gamified elements in influencing individual's motivation to encourage repeated or continuous behavior. In particular, application of gamification has been found helpful where long-term commitment is desirable (Koivisto \& Hamari, 2019). The authors argue that the use of game elements in work (Faisal et al., 2019) like badges, leader boards, points, avatars, etc. can encourage motivation through competition (Sailer et al., 2017). It can also make the work more enjoyable which in turn can increase the gig workers' satisfaction and thereby their productivity. While the applications of work-based gamification are numerous, its role in engaging the gig workers is not adequately understood (Keith et al., 2019; Faisal et al., 2019; Poon, 2019).

Further, Friedman (2014) emphasized that in situations where there are uncertainties, and there is no overarching theory that explains the phenomenon perfectly, it is essential to draw insights from multiple theoretical lenses. This study, therefore, integrates the social exchange theory (SET) and self-determination theory (SDT) to provide a comprehensive understanding of gig workers motivation, to stick to a digital earning platform. Work and functioning of gig tasks and the worker's decision to stay or quit, are governed mainly by social exchange theory (SET) which claims that the exchange between employees and firms will continue to happen if the cost-benefit analysis is in favor of the employee. Insights from the self-determination theory (SDT) are drawn to help explain, how extrinsic and intrinsic motivation will help the gig workers stay more satisfied and highly productive, which will inhibit their chances to quit the gig ecosystem. Overall, using the theoretical lens of SET and SDT, the study aims to examine how can gamification help in controlling the "intentions to quit" of the gig workforce engaged on online platforms.

This study contributes to the existing body of knowledge in the following three ways. Firstly, it expands the current theoretical and practical understanding of gig workers operating on online platforms by layering the current knowledge of employee engagement with a mixed theoretical approach using SET and SDT. This, in turn, helps explaining the factors that can reduce the chances of gig workers to quit the gig platform. It is established that the use of gamification as a motivational tool, can help prevent the gig workers from fatigue and reduced 
motivation that is caused by the unconventional nature of gig work. Second, the study offers a novel perspective on the mitigating the impact of the dark side of the gig economy by virtue of proper system design. Finally, the study contributes to the existing and growing body of knowledge on gig workforce, which is scarcely discussed in both academic and practical worlds. Additionally, the study also raises implications regarding the existing engagement practices followed by gig employers to run their business without compromising the quality of work.

The paper is divided into seven sections. Section two provides an in-depth review of the literature on gig economy and gamification. This section also discusses the theoretical foundations of SET and SDT in the context of gamifying the gig work. Section three discusses the research hypotheses and theoretical model. The next two sections discuss the research design and the subsequent results. Following which the theoretical and practical implications are discussed in section six which sheds light on the contributions of the study and offers a critical debate between the results of the current study and the previous ones. In the end, section 7 lays out the conclusion, limitations of the study, and provides constructive recommendation for future researchers.

\section{Literature Review and Theoretical Underpinning}

\subsection{Gig Economy}

The gig sector has gradually gained attention and importance amid the changing nature of business. Gillispie (2017) defined the digital contractual workforce as "gig employees," thereby offering what we know today as the "new economy." While the gig workforce has been growing, there remains ambiguity in its operational definition (Kilhoffer et al., 2017). While there exists no formal definition of its breakup of the sector, studies have classified it into two sectors based on the kind of work done by gig workers: blue collared and white collared (Kilhoffer et al., 2017; Gillispie, 2017). A white collared gig worker is a person who performs professional, desk, managerial, or administrative work. Hasija et al. (2020) in their recent HBR article discusses the rough boundaries of skilled white gig workers by pointing to works that involve consultation and management. The workers belonging to this category are highly skilled and possess high knowledge to perform specific tasks. Thus, they can be treated as specialists available in the freelancing space. Most of the published literature discusses three critical dimensions of gig work: high degree of autonomy, payment against completion of task/assignment, and short-term relationship between employee and employer. Further bifurcations of gig workers are based on their engagement in the online-offline model, whitecollar or blue-collar jobs, individual or crowd work (Kässi and Lehdonvirta, 2018; Rockman et al., 2018). The growth of internet led services that involve gig workers has primarily shifted the gig workforce to online platforms. Multiple platforms engage gig workers with gig employers. Wood et al. (2019) and Meijerink and Keegan (2019) observed all three players in the gig economy - the employer, the employee, and the platform.

Petriglieri et al. (2018) reported that gig work was usually seen as extra work performed, especially in the case of blue-collar gig workers; they used this as an opportunity to develop supplementary income sources. It was found that with white-collar online gig workers, there are issues related to higher autonomy leading to lower engagement and a mismatch between job characteristics and job deliverables. While the growth in the number of people joining the gig workforce is significant, the number of dropouts is equally substantial (Gandhi et al., 2018; 
Faisal et al., 2019). Jabagi et al. (2019) indicated that a lack of commitment and an unregulated work environment often translates into lower quality of deliverables and quality of work.

Manyika et al. (2016) noted that in the context of white-collar jobs, the rising trend in gig work enrolment is mostly driven by choice and not by necessity; however, it is exactly the opposite for blue-collar gig work. Contrarily, studies have also discussed various reasons pertinent to the dark side of gig work, and a lack of motivation is one of the listed reasons (Pichault\& McKeown, 2019). It is imperative to understand that while motivation drives people to join the gig workforce, its absence also leads to gig workers opting out thereof (Poon, 2019; Friedman, 2014). Therefore, it is vital to identify a theoretical lens that will put light on the switching motivational behaviour of gig workers or any mechanism that may will help explain how gig workers can remain in the gig economy.

So far it had been identified that the work profile of gig workers and the tasks they undertake are vital criteria that decide the outcomes of their intentions to continue in gid roles (Healy et al., 2017; Stewart \& Stanford, 2017). Knowing that attrition rate and switching rate among gig workplaces is high, it is important to understand theoretical and practical ways to engage the gig workforce. The next section discusses, both theoretically and practically, the role of gamification in motivation and engagement of people.

\subsection{Gamification and its application in gig sector}

Gamification is defined as an "application of game-design elements and game principles in non-game context" (Robson et al., 2015, p.411). Similarly, Werbach (2014, p267), defined gamification as "the process of making activities more game-like", in order to bring academic and practitioner perspectives closer together. Non-game context applications include marketing, teaching, learning, human resource management, health and fitness, etc. Cardador et al. (2017) discussed the theory of work gamification; they broadly proposed using game artifacts or game features in the working of an organization/employee to enhance productivity and promote desired work behaviour. Most common game artifacts used by firms are points, badges, leader boards, levels and character sheets (Kapp, 2012; Dale, 2014). The phenomenon of gamifying work in a company or for an individual is mostly captured by employee's motivation. Often, firms use gamified plans to engage employees. The most common plans include awarding titles to employees like "employee of the month," "best manager," etc. The use of such practices by firms is also categorized under enterprise gamification (Ruhi, 2015). Some prominent examples are: the Salesforce initiative, Hunt for Chickens; Coca Cola's initiative, "My Coke Rewards"; Nike's initiative, "Cheers"; "My Marriot Hotel" for recruitment in Marriot hotels; "Escape Room" activity designed by Phoenix software; etc. Such applications have helped firms to deal with most of the issues listed in the Octalysis framework - meaning, accomplishment, ownership, scarcity, avoidance, unpredictability, social influence and empowerment.

When considering the application of gamification in the context of human resource management, it is reported that firms use game mechanics at almost every step of human resource management, from recruitment drives to exit interviews (Cardador et al., 2017; Swacha \& Muszyńska, 2016). It has applications both within and outside the organization. Studies report that gamification has helped firms operate better in situations of uncertainty, and with people not on the payrolls of the firm. The role of gamification assumes greater importance where the firm deals with freelance employees, free agents, casual workers, parttime employees, clock hour based workers, or gig workers (Lehdonvirta, 2018; Carr et al., 2017) 
because gamification has the ability to engage the attention of gig workers who are switchers. Schwellnus et al. (2019) reported challenges related to loyalty, quality of work, and misuse of autonomous power. The application of game elements in the gig economy has been very recent. The primary reasons for lower engagement as reported by Petriglieri et al. (2019) include low enrolment rate, delay in completion of task, high dropout rates, lack of motivation to be part of the gig workforce, seasonal behavior of gig workers, etc. To address most of these issues, gig employers have started practicing game-based work engagements (Huang et al., 2020). Some of the prominent ones are as follows:

Lyft, a ride-hailing app, uses an algorithmically generated "challenge" for every driver to complete a predefined number of rides in a stipulated time to unlock a reward. Mostly, this cash-based reward is in the form of a bonus. Occasionally, they fix such tasks once every week to increase the value of the reward. A similar practice is also followed by their competitor, Uber (Berger et al., 2019). The task assigned by Uber aims to ensure availability of drivers at peak hours at locations where there is relatively high demand. Drivers are also offered extra perks to drive late hours to meet customers' requirements. Both these firms celebrate the performance of drivers by asking customers to rate them and award them badges (Scheiber, 2017; Morschheuser et al., 2019). Drivers with a higher rating are then promoted to a cadre that offers them a better chance of getting the subsequent customer.

Amazon offers delivery boys extra perks to deliver packages on promised dates (Wood et al., 2019; Çeker and Özdaml, 2017). Delivery rating for the delivery person is further linked to other factors like polite behavior, punctuality, damage-free deliveries, timely pickup for return, etc.

Firms also engage and reward teachers, trainers, and tutors for offering services to students. Coursehero and Chegg grants online tutors' badges (badges denote bonus) for helping students in solving problems and finishing homework/class assignments. Tutors are also placed on a leader board that accounts for the number of questions correctly answered by a gig tutor and the speed at which the answer was given.

Similar practices are followed by other gig firms. Applied gamified principles have helped gig employers gain better control over gig workers (Heeks, 2017; Gleim et al., 2019). Firms have reported a better engagement rate and greater motivation in their workforce (Brown, 2009). Moreover, reward driven gamified practices enable a balance of autonomy, freedom, and work control without impacting quality of deliverables and loss of critical resources like time and intellectual capital. Gamification acts like a cue that helps in improving their experiences and motivates them to be more participative. This in turn helps firms to use gamification as a tool to combat the dark side of engagement. Similarly, Kumar (2013) asserted that game features like points, leader boards, badges, and avatars made employees more engaged in work and increased their productivity by boosting intrinsic and extrinsic motivation. To foster the discussion further theoretically, we now present a detail debate on the theoretical aspects of engagement. The use of theoretical lens will help in understanding the phenomenon and interlinkages between the core constructs that drive engagement and help us understand how game artifacts can trigger a positive behaviour.

\subsection{Social Exchange Theory (SET)}

Social Exchange Theory is based on the psychological and sociological foundation that aims to study social behavior during interactions between two parties (Emerson, 1976). The theory 
proposes that social behavior is a result of the exchange process that minimizes cost and derives the maximum benefit (Blau, 1964). Homans (1961; 1967) argued that individuals carried out cost-benefit analysis after weighing the risk involved in social trade. As the risk quotient grows, people tend to quit the relationship. Cost versus benefit analysis mostly considers inputs such as time, money, or effort, and returns are often proxied by rewards that are either tangible or intangible. As the theory is grounded in psychological and sociological literature, its application is largely seen in human resource management (Cook et al., 2013), labor relations, and service/product-based relationships between firm and customer (Cropanzano \& Mitchell, 2005). Recent studies have also discussed its application in gig work (Biron \& Boon, 2013). Social exchange is based on the pillars of self-interest and interdependence. Interdependence is explained mostly by individualism as a phenomenon in the exchange process, while self-interest is often studied as a combined effect of psychological and economic needs (Cropanzano et al., 2017). The application and use of social exchange theory were also proposed through twelve theoretical propositions by Nye (1978). In the context of the nature of gig work, some of the theoretical propositions applicable are: a) costs and other rewards being equal, individuals choose statuses and relationships that provide the most autonomy; b) immediate outcomes being equal, they choose those alternatives that promise better long- term outcomes. Thus, the theory is mostly linked to performance derived from a given set of efforts in a preferred autonomous setting. However, in the absence of rewards and benefits or in a scenario that involves high risk with lower returns, there is a stronger tendency to exit the social exchange relationship (Liu et al., 2020; Stanford, 2017). Therefore, SET principally helps in explaining the act of continuance or discontinuance by gig workers.

In other words, in a social exchange relationship between gig workers and employers, gig workers' intentions to quit are driven mainly by factors involving a higher degree of risk or work fatigue (Stanford, 2017; Fisher \& Cassady, 2019). Thus, workers who see a bleak future in monetary or social rewards are likely to quit.

While the social exchange theory explains how and under what circumstances it works, there is a need to examine the antecedents of gig workers' motivation through a different lens. Moreover, it is essential to look at the intrinsic and extrinsic motivation of gig workers to reduce their intensity to quit (Brawley, 2017; Wienner et al., 2020). Therefore, we explored theories of organizational behavior and found social determination theory most suitable for our current study.

\subsection{Self Determination Theory (SDT)}

Self Determination Theory represents a broad framework that explains the motivation of an individual (Deci \& Ryan, 2012). It is based mainly on the constitutional argument that an individual's motivation has two facets - intrinsic and extrinsic (Deci \& Ryan, 2002; Gagné \& Deci, 2005). Intrinsic and extrinsic motivation are based on cognitive and social development that stems from individuals themselves. The theory also focuses on how cultural and social factors (Wu et al., 2016) promote or demote an individual's ability to take initiative, their wellbeing (cognitive and psychological), and the quality of their performance. The theory is based on the three pillars of relatedness, competence, and autonomy (Deci \& Ryan, 2008) that fosters a sense of motivation leading to greater engagement, better performance, more persistence, and enhanced creativity. Deci and Ryan (2008) discuss three key elements of the theory. First, individuals are powerful beings who can master their inner self mostly by 
keeping a check on their emotions. Second, individuals have an inherent tendency to grow by contributing functionally to their work. Third, optimal actions and developments do not happen automatically with individuals and usually require an external push. Thus, the growth in motivation is triggered primarily by an external drive that this study proposes to establish using gamification. The use of gamification justifies the increase in motivation (intrinsic and extrinsic), engagement, performance and satisfaction, all of which are leading indicators of increase in productivity (Shi \&Cristea, 2016; Sailer et al., 2017; Landers et al., 2015; van Roy \& Zaman, 2019).

The three components of the theory (autonomy, competence, and relatedness) also fall in line with the nature of the work of a gig employee. Recent studies have pointed out that intrinsic motivation, which is often a result of one's choice to opt for a gig task on a platform, results in gig workers scoring high on autonomy (Lehdonvirta, 2018; Poon, 2019). Zuckerman et al. (1978) asserted that when given a choice, an individual selected options that they loved, which drove their intrinsic motivation. This explains the connection between intrinsic motivation and gig work. Competence is another critical piece explaining motivation and is often explained by feedback (Morschheuser et al., 2019). With greater positive feedback, motivation tends to be higher; creating a competitive environment also improves productivity. Game elements like points and leader boards resemble factors required to enhance competence; these lead to gig employee satisfaction and enhance productivity (Sepehr \& Head, 2013; Weber et al., 2018). The last aspect that explains motivation better is relatedness. It is often used interchangeably with belongingness. It is acknowledged that choice of work and a high degree of association or belongingness are a few of the prime reasons people opt for gig work. Gig work, often discussed as an extension of freelance work, offers (by its very nature) the freedom to choose the kind of work (Blanchard et al., 2019; Poon, 2019). Online platforms also allow gig workers to post their expertise and experience to attract gig employers. Moreover, the application of game artifacts in work-related tasks strongly explains attachment-motivation relations between gig employer-employees (Hamari et al., 2014; Huotari \& Hamari, 2017).

We looked at the strengths and weaknesses of both the theories and found that SET helped in explaining the trade-off between the efforts and resources that went into performing the task, and the rewards expected by a gig employee considering the risks involved in the transaction. While it is documented in the literature that with higher risks in job roles, there lies a higher chance for the employees to quit, it becomes interesting to understand the same behaviour in the context of gig workers. Unlike full time jobs which are largely dominated by the company policies and fixed job roles, gig work has weak regulatory frameworks which causes a drop in the risk levels as well. Moreover, as gig workers are in commanding position to decide to work on any work assignment or not, it becomes important to understand their mental position and decision making abilities to evaluate risk levels and stay motivated at their job. In the lack of external regulations, the power of intrinsic motivation holds larger significance which can be initiated by gamified elements. With this backdrop, it becomes important to study the motivation of gig workers from the lens of SDT and SET. The next section discusses each of the proposed hypotheses.

\section{Hypotheses Development}

We explore the association between organizational-level variables and their effect on individual performance in the context of an online engagement platform. Huselid (1995) postulated a positive association between HRM practices adopted by firms and employee 
performance. While the seminal study listed multiple variables that could measure employee performance, job satisfaction is one of the key drivers that have been studied often in literature (Gannon et al., 2015; Chang et al., 2011). Locke (1976) described job satisfaction as a "positive emotional state arising from an individual's subjective experience of their job" (p.1300). Recent literature asserts that job satisfaction is quite often the driver of an employee's stint with an organization, therefore, it becomes important to explore specific factors that could help in enhancing job satisfaction (Zhang et al., 2013; Gracis-Chas et al., 2016). High Power Work Systems (HPWS) is reported to be such a key antecedent that has shown a positive relationship with job satisfaction in the recently published meta-analytical review (Jiang et al., 2012). It is reported that employees' intrinsic and extrinsic motivation largely drives them to perform better in high-performance situations related to jobs categorized under the HPWS category (Heffernan \& Dundon, 2016). Most of the white-collar jobs listed on the gig platform require a niche skillset, and most of such jobs are classified as HPWS. A gig employee needs to display a far better performance than a normal employee to be considered by the platform to carry out other gig tasks matching their skillset (Fabi et al., 2015). Thus, while employees are largely hooked because of job satisfaction achieved by working in an HPWS engagement, it is worthwhile to examine if a similar relationship exists in an online gig work setting. Therefore, we hypothesize:

H1: High Power Work System (HPWS) has a positive impact on Job Satisfaction (JS) of whitecollar gig workers.

Job satisfaction is one of the key metrics to measure employee motivation. Traditional human resource literature has largely used it for organizations and employees. The association of JS with intentions to quit (ITQ) is grounded deeply in literature as there are dozens of studies that have discussed the relationship. Job satisfaction is a positive driver of success for any organization while intentions to quit depict negative behavior (Fabi et al., 2015; Frenkel et al., 2013; Behravesh et al., 2019). Thus, there exists an inverse relationship between the two. The relationship is also substantiated by meta-analysis literature (Gracia-Chas, 2016). However, when it comes to gig employees whose association with the firm is not the same as that of a permanent employee, the link between job satisfaction and intentions to quit is not easily understood. It is noteworthy that gig employees have the option to switch multiple platforms and decide whether they want to take up more assignments on a particular online gig platform; thus, by virtue of having more options, gig employees are more empowered than permanent employees (Prabowo et al., 2019; Cardador et al., 2017). The autonomous nature of the work performed by gig workers also makes it easy to decide whether to work on an online platform. Studies have reported that it is the online gig platforms and their engagement strategies that can keep the gig workforce engaged (Gandhi et al., 2018; Meijerink and Keegan, 2019). Holt and Kennedy (2019) opined that white-collar gig workers were offered specific tasks that involved higher intellectual skills. Given this higher level of required performance, it is worthwhile to understand if the relationship between job satisfaction and their intentions for gig workers. Thus, we hypothesize:

H2: Job Satisfaction (JS) has a negative impact on Intentions to Quit (ITQ) of white-collar gig workers.

Aryee et al. $(2016 ; 2012)$ demonstrated that service oriented HPWS had a positive impact on employees' service performance. Most similar studies also factor in an important construct employee training - organized by the firm (Michaelis et al., 2015). Garmendia et al., (2019) 
mentioned that employees who possessed higher order skillsets or had a proven record of better service-related knowledge showed superior performance at the workplace. Literature also supports the practice of paying higher compensation and retaining employees performing HPWS tasks and whose service performance is consistently better than the average (Wagner et al., 2012; Guest, 2017). This can also be supported using the AMO model which discusses three key components of serviceability - knowledge, ability, and skills - which translate into better performance (Van Rhee \& Dul, 2018). A white-collar gig employee also possesses these elements in different proportions and exhibits them according to the nature of the work. Thus, the performance of a gig worker who is involved in HPWS tasks is largely accounted for by the firm using different metrics. We draw insights from the AMO model which postulates that service motivation enables job performance in the context of gig workers (Guest, 2017; Ornek et al., 2020). As part of the onboarding mechanism, gig workers have to perform tasks that are shorter duration that are often classified under HPWS based on the level of skills and expertise required to perform those tasks. With such short durations, high skill work environments, and lesser gig workforce autonomy for gig employers), gig worker performance could be uncertain. It is therefore important to test the relationship between HPWS and job performance in the context of the online gig workforce. We therefore postulate:

H3: High-Performance Work System (HPWS) has a positive impact on Performance (PM) of white-collar gig workers.

Human resource studies have discussed how and why employee burnout triggers behavior and intentions to quit the job. This relationship is often explained using conservation of resources theory (Hobfoll et al., 2000) which calls "to maintain the employees' well-being, by constructing and sustaining resources in such a way that employees use the available resources to guard themselves against the negative consequences of stressful experiences." Treuren (2019) based their study on this theoretical framework and explained the positive impact of fatigue and burnout on employees' intentions to leave the organization. Much of existing literature also offers similar results, but mainly examines organizations and their employees. Considering the work culture and engagements that an online gig platform offers (Lertxundi \& Landeta, 2011; Wu et al., 2015), burnout is perceived differently. It is of value to examine high performing gig workers' intentions to stay (or quit). Gig stems from the concept of freelance or independent work, and the idea of burnout is mostly not applicable here (Jyoti \& Rana, 2019) due to the presence of a high degree of flexibility and autonomy for a gig worker in opting for a job. There is a greater chance of gig workers performing better if the work environment is selected by them. But the same autonomy and flexibility make the gig workspace an easy pathway to enter as well as exit (Jyoti \& Rana, 2019; Gracia-Chas et al., 2014). With an increase in gig workstations and gig opportunities, gig employers need to retain high performing gig employees to run their business (Cafferkey \& Dundon, 2015). Similarly, a gig platform that encourages and empanels high performing gig workers will face lesser attrition rates; we test this conjecture and propose:

H4: Performance (PM) of white-collar gig workers has a negative impact on Intentions to Quit (ITQ).

We referred to the seminal definition by Tett and Meyer (1993) conceptualizing "Intentions to Quit" in our study. While it is not considered a behavioural outcome, ITQ is still treated as a key factor contributing to a firm's performance matrix. Backed by cognitive withdrawals, the "intentions to leave" construct is often ranked very high when assessing the performance of a 
firm (Fugate et al., 2012). Kundu and Gahlawat (2016) postulated that in countries where there is greater competition due to the availability of a similarly skilled workforce, intention to quit is an important marker in terms of defining competitive advantage. Companies with happy employees and workforce witness lesser intentions to quit. We explored extant literature for enablers and barriers to ITQ, and out of multiple prominent factors, HPWS was recorded as a critical barrier (Kehoe and Wright, 2013; Boon et al., 2011). A study by García-Chas et al. (2014) claimed that high-performance work practices like rewards and employee participation, result-oriented appraisal, job security, extensive training, and rigorous staffing had a negative impact on ITQ. Thus, an employee rated highly on the parameters of HPWS would be less likely to leave the organization. While there are other factors like performance, procedural justice, intrinsic motivation, etc. that control the overall nature of ITQ (Gkorezis et al., 2018), the underlying relationship does not change. It is reported that HR systems and staffing rules adopted in gig employment are different. However, the nature of gig employment makes it difficult for the firm to retain the gig worker. It is reported that gig workers continue to work with gig employers because of their needs which may be temporary or permanent (Behravesh et al., 2019). Other reasons to continue could include nature of job, work culture of the organization, and competition in the market. In recent years, firms have incorporated HPWS to manage gig employees. There are limited studies examining whether HPWS would have a negative effect on intentions to quit. Thus, drawing from what is known from published literature, we hypothesize:

H5: High-Performance Work System (HPWS) has a negative impact on Intentions to Quit (ITQ) of white-collar gig workers.

Cardador et al. (2017) discussed the importance of work gamification in conceptualizing how game mechanics could help improve performance of employees (de Marcos et al., 2014; Hamari, 2013). Performance management of employees is primarily driven by their level of intrinsic motivation. The hook offered by game mechanics helps generate interest among workers in the short term (von Roy \& Zaman, 2019). Game elements like points, badges and leader boards enhance employee performance by offering an informative and effective mechanism to be connected with their task (Cardador et al., 2017). Gamification can be applied to both offer feedback and intrinsically motivate employees. Feedback is provided as encouragement as well as suggestions for improvement. Most gamification-based studies have discussed how game elements positively influence intrinsic motivation, which boosts productivity (Haivas et al., 2013; Mekler et al., 2017; Xi \& Hamari, 2019). Gamified applications work better in situations of unpredictability and scarcity, both of which are elements of the octalysis framework (Chou, 2019). While studies have primarily claimed that gig workers possess a high degree of freedom, the dark side of gig employer-gig employee engagement highlights issues related to discipline and regularity in work regimes. Thus, with freedom, there comes a degree of risk in this engagement that needs to be managed using appropriate engagement mechanisms (Shatz, 2015). The gamified platform would help them gain higher job satisfaction.

It is important to examine competitiveness in situations where there is no interaction between participants, though similar jobs are being performed (Morschheuser et al., 2019; Kumar, 2013). Firms like Ola, Uber, Zomato, etc. use game mechanics driven engagement approaches to acquire and retain drivers and delivery agents. One of the main shortcomings of whitecollar gig work is the nature of work and its specific demands. Unlike blue-collar jobs with 
firms like Uber, white-collar gig work demands a different category of craft, which at times, is rare (Holt \& Kennedy, 2019). Also, gig workers may or may not at times agree to the compensation offered. Therefore, firms need tangible reward-based mechanisms to retain such workers. Competitive strategies need to be used to maintain a strategic advantage; gamification is one such strategy.

We, therefore, base our arguments on both the perspectives and propose to explore the relationship between HPWS and performance, and HPWS and job satisfaction of gig workers. Another prime reason for examining the effect of gamification on job satisfaction and performance is that both are antecedents that have a negative relationship with "intentions to quit" (Redondo et al., 2019; Masood et al., 2020). Therefore, while assessing the link between performance and job satisfaction of gig workers, we observe the role of gamification as moderator. The study proposes:

H6a: Gamification (GM) has a positive moderating effect on the relationship between HighPerformance Work Systems (HPWS) and Job Satisfaction (JS).

H6b: Gamification (GM) has a positive moderating effect on the relationship between HighPerformance Work Systems (HPWS) and Performance (PM).

The study offers new dimensions to explain motivation, performance, and job satisfaction of gig workers in the context of gamified online platforms engagements and reduce attrition. The proposed theoretical model with hypotheses is shown in Figure 1.

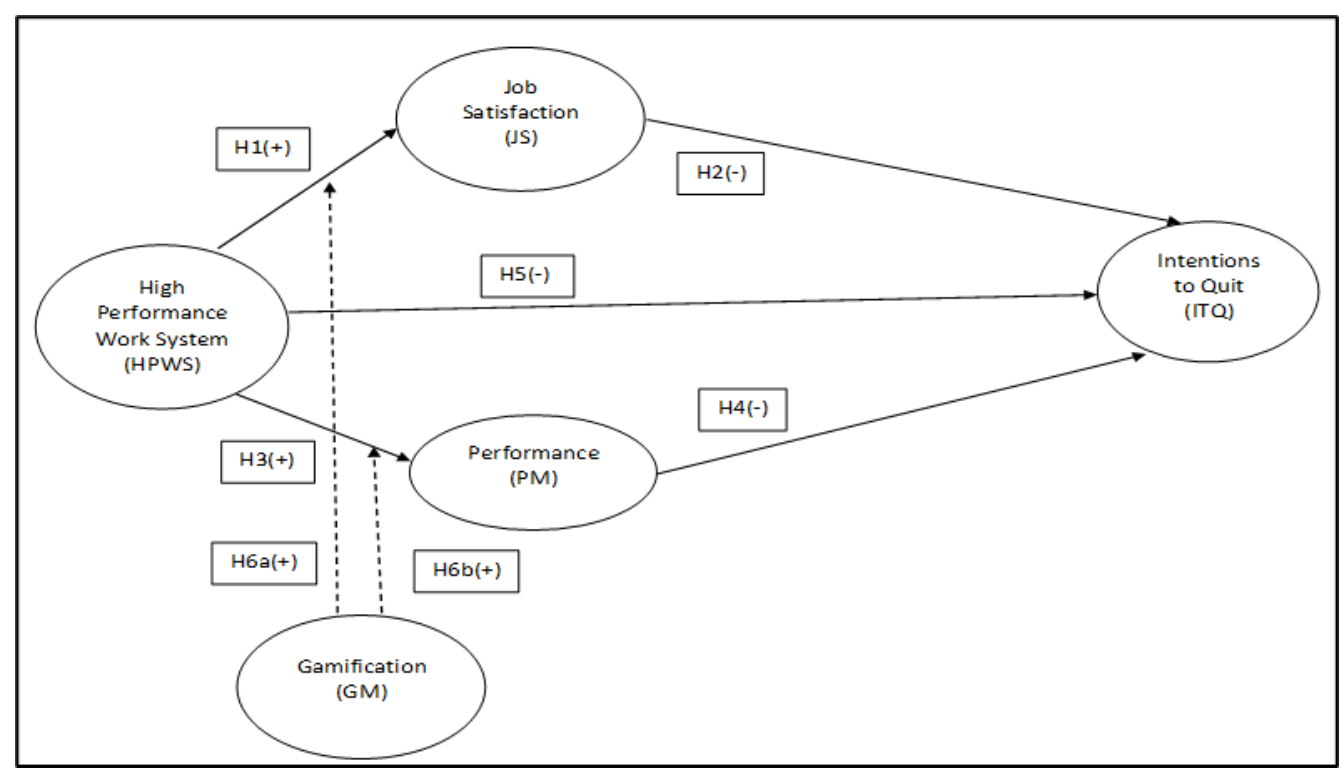

Figure 1. Theoretical Model

\section{Research Design}

We collected primary data to test the proposed research hypotheses. Primary data was collected using a structured questionnaire pre-tested from 12 academicians each having more than five years of experience and have published their work in a related area of study. Seven human resource professionals working with firms in the online gig workspace was invited to pre-test the questionnaire. Suggestions received from both groups were used to modify the questionnaire in terms of length, positioning of questions, and wording. The final questionnaire was then used for data collection. Data were collected from gig workers working 
with online platforms operational in primarily Asian countries. We now discuss the operationalization of constructs as it is a critical step in designing a psychometrically sound survey instrument.

\subsection{Research Instrument and operationalization of the constructs}

We designed the initial questionnaire on the basis of existing scales for each of the constructs. Scale adoption was discussed with renowned academics who had published empirical research using one or more of the constructs used in the study. The panel of academics was contacted over a group video call and based on the unanimous decision made by the panel, the research instrument was finalized. We also approached research scholars and faculty members working in a multi-disciplinary yet related field of work to ask for feedback on the questionnaire. On the basis of our discussions with all knowledge sources, we revised the questionnaire in terms of flow of questions, selection of items, and choice of language. This helped in gaining clarity and removing ambiguity, thus improving validity and maintaining parsimony in the process of iterative feedback. Each of the constructs was drawn from existing literature and modified to the context of the present study. The process of adaptation and finalization of items for each construct was further discussed and approved by a panel of experts. All the constructs used in the study are reflective. HPWS was measured using the scale adapted from Sun et al. (2007). This scale uses eight subscales to assess the eight core HR practices. For employment security," "clear job description," "extensive training," "participation", "results-oriented appraisal," and "incentive reward" subscales, the original number of items was kept. We dropped "selective staffing" and "internal mobility," and for subscales, the number was reduced to three items per subscale. Consequently, the resulting scale comprised 18 items. Job satisfaction was measured with a three-item scale adapted by Lee and Bruvold (2003) from Quinn and Staines (1979) assumed to generate an overall measure of job satisfaction. Job performance was measured using two sub scales measuring role behavior and task performance. The scale for role behavior was adapted from Williams and Anderson (1991) while that for task performance from Bott et al. (2003). We further referred to Ang et al. (2013) to adapt the scale for "intention to quit" which had 3 items. Lastly, for gamification, we adapted the scale from Behl and Dutta (2020) with 9 items.

\subsection{Data Collection}

We searched the archival history of websites using Waybackmachine (https://archive.org/web/) to list down the tasks listed in the past two years (January 2018December 2019). The rationale for using an archival data is to understand the overview of tasks created on different crowdsourcing websites and the degree and skills of engagement required by gig workers. Archival data also helps in understanding the changing needs and requirements posted on the portals across different geographies. However, studies have also reported that data validation is key for archival data to improve the robustness of the results (Lee et al., 2018). We then contacted website owners seeking permission to send a questionnaire to the participants in these tasks. The preliminary search gave us a list of 87 websites that hosted gig work and after scrutinizing them on the basis of rate of completion of tasks, we eliminated the ones whose success rate was less than $30 \%$ (Ye and Kankanhalli, 2017). We reached a total of 34 websites (Refer to Appendix A) that had hosted "gig work" in the given period. A total of 1567 respondents were contacted out of which 374 respondents filled the survey. We sent repeated reminders to respondents to fill the questionnaire. The respondents confirmed that they had contributed to listed tasks on the given website, which 
was validated by task creators and website managers. The three-level validation helped us to reduce self-reporting bias in our data.

Respondents participated in one or more tasks hosted on one or more websites. The tasks ranged from higher degree of creativity (including designing, photography, writing, music, etc.) to lower degree of creativity (data entry, data collection, making cold calls, etc.). Most of the respondents were relatively young (average age 23.4 years) and from tier 1 cities. We ensured that in our final dataset, tasks creators and task solvers belonged to different nationalities. This helped us control the data and reduce the chances of bias during the data collection process. As gig workers were paid in their local currency, domicile effect was controlled during data collection. We further tested non-response bias by following guidelines by Armstrong and Overton (1977). We performed a t-test to compare the performance attributes (like average time spent on gig work) of respondents and non-respondents. Test results reported no significant difference between the two categories $(\mathrm{p}>0.05)$. The profile of the respondents is tabulated in Table 1. The next section discusses the tools used to test hypotheses, key results of the analysis performed, and the rationale behind the procedure followed at each step.

\begin{tabular}{|l|l|l|}
\hline Demographic Variables & Classification & No. of respondents \\
\hline Number of gig work done in the past 24 months & 0 to 5 & 156 \\
\hline & 5 to 10 & 87 \\
\hline & 10 to 15 & 46 \\
\hline & 15 to 20 & 31 \\
\hline Average Time Spent per task & More than 20 & 54 \\
\hline & Less than 6 hours & 165 \\
\hline & 6 to 12 hours & 97 \\
\hline & 12 to 18 hours & 63 \\
\hline & 18 to 24 hours & 40 \\
\hline Average money earned per task & More than 24 hours & 9 \\
\hline & Less than $\$ 250$ & 201 \\
\hline & $\$ 250-\$ 750$ & 126 \\
\hline & $\$ 750-\$ 1250$ & 41 \\
\hline Gender & More than $\$ 1250$ & 6 \\
\hline & Male & 188 \\
\hline & Female & 185 \\
\hline & Transgender & 1 \\
\hline & & \\
\hline
\end{tabular}

Table 1. Demographic Profile of Respondents

\section{Data Analysis and Results}

\subsection{Common Method Bias (CMB)}

We collected data using a single source (survey-based questionnaire) which might result in common method bias (Lindell and Whitney, 2001). Ketokivi and Schroeder (2004) explained 
that in order to resolve the issue of common method bias in survey-based research, one needs to use multiple informants for each of the observational units. Some of the key reasons reported by Podsakoff et al. (2003) for common method bias include social desirability and consistency motif. Therefore, we followed the guidelines of Guide and Ketokivi (2015) to minimize the chances of committing common method bias. As the first step, we requested the respondents to refer to the details of the deliverables shared with them before accepting the terms and conditions to perform the gig work. Based on the data and information, the respondents were asked to answer the questions. We also performed Harman's single factor test and found that maximum covariance explained was $36.18 \%$ which was lesser than the threshold (50\%), thereby confirming that the data did not suffer from common method bias. Referring again to Lindell and Whitney's (2001) guidelines, we performed a marker variable test by introducing a marker variable that was theoretically unrelated to the dependent variable. We found a low correlation between the categories of marker variable (different tiers of cities of residence of respondents) and independent and dependent variables. As the last step, we referred to model wide collinearity assessment proposed by Kock (2015). This test acts like a litmus test that helps measure the extent to which the measurement instrument can establish generalizability of results. Variance inflation factors (VIF's) for each of the constructs reported values less than the threshold value of 3.5. The battery of tests confirmed that the data did not suffer from CMB.

\subsection{Validation of Measurement Instrument}

We used Partial Least Square (PLS) Structured Equation Modelling (SEM) as compared to covariance-based SEM. Henseler et al. (2015) point out a key advantage of using PLS-SEM estimates are more generic and less affected by model misspecification in some subparts of the model (Dubey et al., 2019). It is also known that PLS-SEM is better suited for exploratory models and theory development and has a higher degree of relaxations related to the normality of data (Chin, 1998; Gefen \& Straub, 2005). It is known that PLS-SEM is used when the objective is predicting target constructs and the structural model has purely formative constructs. Also, Hair et al. (2011) and Hair et al. (2017) confirmed that it is advisable to use PLS-SEM when the research is exploratory or an extension of existing theoretical structure unlike in Covariance based SEM (CB-SEM), that works on the principle of theory testing. The present study fits into the framework of theory integration and exploratory in nature, thereby making PLS-SEM a better choice to be used in this case. To test the hypotheses, we used WarpPLS 6.0 software. We also drew inspiration and guidance from Peng and Lai (2012) who argued that PLS works on prediction orientation and helps in assessing the predictability of the exogenous variable.

We examine how "intentions to quit" can be explained by a set of antecedents, thus, it is vital to calculate each antecedent's explanatory power. Moreover, in the context of the gig economy, the rate of dropouts and underlying intentions are not explained by any established theory. This makes PLS based modeling more appropriate and suitable in the given context (Henseler et al., 2015). The proposed model is complex, thus, to calculate the estimations for each of the predictor variables, we used a two-step approach proposed by Peng and Lai (2012). The first step evaluates the reliability and validity of the measurement model, followed by analysis of the structural model in the next step. We now discuss both the steps in detail. 


\subsection{Assessment of Measurement Model}

\begin{tabular}{|c|c|c|c|c|c|c|}
\hline Construct & Items & $\begin{array}{l}\text { Factor } \\
\text { Loading }\end{array}$ & Variance & Error & $\begin{array}{l}\text { Scale } \\
\text { Composite } \\
\text { Reliability } \\
\text { (SCR) }\end{array}$ & $\begin{array}{l}\text { Average } \\
\text { Variance } \\
\text { Explained } \\
\text { (AVE) }\end{array}$ \\
\hline \multirow[t]{18}{*}{ HPWS } & HPWS1 & 0.81 & 0.66 & 0.34 & \multirow[t]{18}{*}{0.87} & \multirow[t]{18}{*}{0.61} \\
\hline & HPWS2 & 0.73 & 0.53 & 0.47 & & \\
\hline & HPWS3 & 0.85 & 0.72 & 0.28 & & \\
\hline & HPWS4 & 0.72 & 0.52 & 0.48 & & \\
\hline & HPWS5 & 0.88 & 0.77 & 0.23 & & \\
\hline & HPWS6 & 0.71 & 0.50 & 0.50 & & \\
\hline & HPWS7 & 0.80 & 0.64 & 0.36 & & \\
\hline & HPWS8 & 0.68 & 0.46 & 0.54 & & \\
\hline & HPWS9 & 0.77 & 0.59 & 0.41 & & \\
\hline & HPWS10 & 0.70 & 0.49 & 0.51 & & \\
\hline & HPWS11 & 0.78 & 0.61 & 0.39 & & \\
\hline & HPWS12 & 0.84 & 0.71 & 0.39 & & \\
\hline & HPWS13 & 0.74 & 0.55 & 0.45 & & \\
\hline & HPWS14 & 0.69 & 0.48 & 0.52 & & \\
\hline & HPWS15 & 0.88 & 0.77 & 0.23 & & \\
\hline & HPWS16 & 0.82 & 0.67 & 0.33 & & \\
\hline & HPWS17 & 0.75 & 0.56 & 0.44 & & \\
\hline & HPWS18 & 0.89 & 0.79 & 0.21 & & \\
\hline \multirow[t]{3}{*}{ JS } & JS1 & 0.77 & 0.59 & 0.41 & \multirow[t]{3}{*}{0.81} & \multirow[t]{3}{*}{0.68} \\
\hline & JS2 & 0.81 & 0.66 & 0.34 & & \\
\hline & JS3 & 0.89 & 0.79 & 0.21 & & \\
\hline \multirow[t]{9}{*}{ PM } & PM1 & 0.75 & 0.56 & 0.44 & \multirow[t]{9}{*}{0.82} & \multirow[t]{9}{*}{0.62} \\
\hline & PM2 & 0.79 & 0.62 & 0.38 & & \\
\hline & PM3 & 0.87 & 0.76 & 0.24 & & \\
\hline & PM4 & 0.74 & 0.55 & 0.45 & & \\
\hline & PM5 & 0.71 & 0.50 & 0.50 & & \\
\hline & PM6 & 0.78 & 0.61 & 0.39 & & \\
\hline & PM7 & 0.84 & 0.71 & 0.29 & & \\
\hline & PM8 & 0.82 & 0.67 & 0.33 & & \\
\hline & PM9 & 0.77 & 0.59 & 0.41 & & \\
\hline \multirow[t]{3}{*}{ ITQ } & ITQ1 & 0.88 & 0.77 & 0.23 & \multirow[t]{3}{*}{0.78} & \multirow[t]{3}{*}{0.65} \\
\hline & ITQ2 & 0.81 & 0.66 & 0.34 & & \\
\hline & ITQ3 & 0.72 & 0.52 & 0.48 & & \\
\hline \multirow[t]{9}{*}{ GM } & GM1 & 0.70 & 0.49 & 0.52 & \multirow[t]{9}{*}{0.83} & \multirow[t]{9}{*}{0.62} \\
\hline & GM2 & 0.84 & 0.71 & 0.29 & & \\
\hline & GM3 & 0.74 & 0.55 & 0.45 & & \\
\hline & GM4 & 0.76 & 0.58 & 0.42 & & \\
\hline & GM5 & 0.81 & 0.66 & 0.34 & & \\
\hline & GM6 & 0.84 & 0.71 & 0.29 & & \\
\hline & GM7 & 0.85 & 0.72 & 0.28 & & \\
\hline & GM8 & 0.72 & 0.52 & 0.48 & & \\
\hline & GM9 & 0.79 & 0.62 & 0.38 & & \\
\hline
\end{tabular}

Table 2. Loading of indicator variables, SCR and AVE 
We checked for individual convergent validity and reliability along with factor loadings. Results reveal that CR values are above the recommended threshold value of 0.7 (Hair and Hult, 2017) which confirms construct reliability. To test convergence validity, we tested the item loadings and found them to be more than 0.7 (Hair and Hult, 2017) and average variance extracted to be more than 0.50 (Fornell and Larcker, 1981). As a follow up step to test for discriminant validity, we calculated heterotrait-monotrait (HTMT) ratio of correlations with fixed cut offs and inferential tests. Following the guidelines of Henseler et al. (2015), we observed that HTMT ratios are found to be greater than 0.85 and are significantly different from 1 (Franke and Sarstedt, 2019) thereby confirming discriminant validity in our data. As suggested by Hair et al. (2018), we also referred to the upper bound of the $95 \%$ of the CI of HTMT and results $(<0.85)$ confirmed disticnct nature of the constructs.

Table 2 reports that measurement item loadings obtained from a confirmatory factor analysis of their respective constructs were above the suggested minimum threshold of 0.50 (Hair et al., 2010), indicating that the items had acceptable convergent validity.

Next, we tested for multicollinearity in our data by performing a full collinearity test that confirmed that all the values of VIF for each of the constructs were greater than 5 (Hair et al., 2014). We applied Bera and Jarque's (1981) test to check for multivariate normality and found that two constructs were not normally distributed. However, as this is not a necessary condition for applying PLS-SEM, we continued using PLS-SEM for further data analysis.

\begin{tabular}{|l|l|l|l|l|l|}
\hline & HPWS & JS & PM & ITQ & GM \\
\hline HPWS & $\mathbf{0 . 7 2}$ & & & & \\
\hline JS & 0.55 & $\mathbf{0 . 8 8}$ & & & \\
\hline PM & 0.68 & 0.43 & $\mathbf{0 . 7 9}$ & & \\
\hline ITQ & -0.11 & -0.05 & -0.03 & $\mathbf{0 . 8 2}$ & \\
\hline GM & 0.32 & 0.57 & 0.54 & 0.38 & $\mathbf{0 . 9 1}$ \\
\hline
\end{tabular}

Note: HPWS: high performance work systems; JS: job satisfaction; PM: performance; ITQ: intention to quit; GM: gamification; Square root of Average Variance Extracted (AVE) highlighted in bold across the diagonal.

Table 3. Correlation among constructs

\subsection{Test for Endogeneity}

The last step performed before testing the hypotheses was testing for endogeneity for the exogenous variable in the model. For example, in our theoretical model, high-performance work systems (HPWS) are considered exogenous with respect to other constructs in the model. Thus, endogeneity is not a concern in our data. Further, we applied Durbin-Wu- Hausman to our dataset (Davidson \& MacKinnon, 1993). The test involved regressing a high-performance work system on all moderating and control variables. We observed that the residual of all parameter estimates was non-significant which indicates that HPWS is exogenous in our model. The results fall in line with the initial conceptualization and operationalization of the construct.

\subsection{Structural Model Assessment}

We used bootstrapping resampling method with 150 resamples to test the structural model. We then tested for the structural model's quality by calculating and reporting the model fit 
indices shown in Table 4 . The table reveals that all the indices were statistically significant and exceeded the respective thresholds as indicated in literature. We can, therefore, conclude the adequacy of our structural model.

\begin{tabular}{|l|l|l|}
\hline Index & Value & $\begin{array}{l}\text { Sig Value (Acceptable Range wherever } \\
\text { applicable) }\end{array}$ \\
\hline Average path coefficient (APC) & 0.311 & $\mathrm{p}<0.01$ (Rosenthal and Rosnow, 1991) \\
\hline Average R square (ARS) & 0.399 & $\mathrm{p}<0.01$ (Rosenthal and Rosnow, 1991) \\
\hline Average adjusted R square (AARS) & 0.376 & $\mathrm{p}<0.01$ (Rosenthal and Rosnow, 1991) \\
\hline Average block VIF (AVIF) & 2.672 & Acceptable if $\leq 5$; Ideally $\leq 3.3$ (Kock, 2015) \\
\hline Tenenhaus Goodness of Fit (GoF) & 0.489 & $\begin{array}{l}\text { Large } \geq 0.36 ; \text { Medium } \geq 0.25 ; \text { Small } \geq 0.1 \text { (Tenenhaus } \\
\text { et al., 2005) }\end{array}$ \\
\hline
\end{tabular}

Table 4. Model fit indices

We also performed a multi group analysis (MGA) using Measurement Invariance of Composite Models(MICOM) approach (Henseler et al., 2016). We followed a three-step approach wherein we calculated configural invariance to begin with, followed up with compositional variance and lastly evaluating equality of composite means and variances between groups. Henseler's MGA technique uses p-value difference between path coefficients that are either higher than 0.95 or lower than 0.05 thereby confirming that the groups are statistically different. We performed the steps for all the hypotheses with groups like gender, frequency of gig work, time invested, and money earned. The results reveal that there is no significant different between men and women (we did not test it for Transgender), between four levels of frequency of engagement of gig workers, however there was a significant difference found between groups for time invested on an average to perform tasks and the amount earned. The probable reasons for the same could be dependent on the type and complexity of tasks which results in a gig worker investing more time and earning more money. Brawley (2017) also confirmed that the reason for this could also be dependent on the platform and its operational requirements as well.

\subsection{Results of Hypotheses Testing}

Figure 2 presents the results of the proposed model estimates, e.g., the standardized path coefficients associated with each proposed hypothesis, the significance of the path coefficients, and the variance explained $\left(\mathrm{R}^{2}\right)$ by the independent variables. We also summarize the results in Table 5 which shows the results of the tested hypotheses. All proposed hypotheses were supported except the relationship between HPWS and ITQ. Results show that the independent variable in the model i.e., "intentions to quit" explains $73.2 \%$ variance, while job satisfaction and productivity explain $43.4 \%$ and $35.8 \%$ variance, respectively. Results confirm a significantly positive impact of HPWS on the job performance of gig workers $(\mathrm{H} 1)(\beta=0.42, \mathrm{p}$ $<0.001)$, and significant positive impact of HPWS on the productivity of gig workers $(\mathrm{H} 3)(\beta=$ $0.56, \mathrm{p}<0.00)$.

The last dimension that explains the phenomenon of dropping out of the online platforms is HPWS, wherein we found counter-intuitive results(H5). Referring to the results $(\beta=-0.014)$, we confirm that the functions under HPWS are either functionally or administratively different, and do not negatively impact gig workers' motivations. Reflecting upon the underlying cost-benefit analysis framework drawn using social exchange theory, the phenomenon of disengaging with the online platform has mixed results. We then tested if gamification could help improve upon the two prominent antecedents - job satisfaction and 
productivity of gig workers. As discussed in literature, game artifacts induce intrinsic and extrinsic motivation among people. Its importance and relevance become greater in the context of an unregulated and autonomous environment. Both hypotheses - H6a and H6b - were supported and a significantly positive moderating relationship was found between HPWS and JP, as well as HPWS and PM. Results also help in explaining the worker's motivation from the lens of SDT. A highly motivated and performance-driven worker is less likely to quit, and results support the proposition.

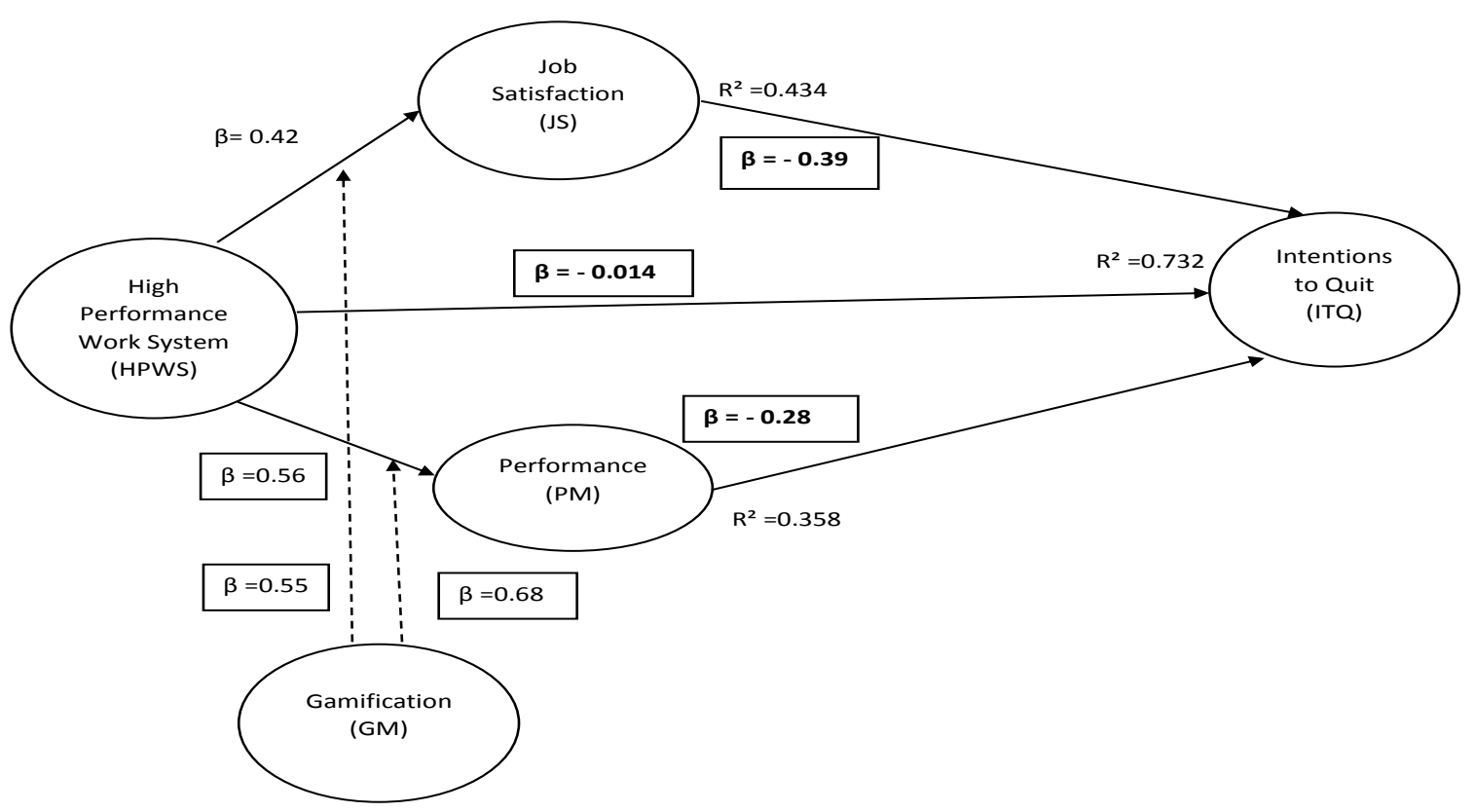

Figure 2. Final SEM Model

\begin{tabular}{|l|l|l|l|l|l|}
\hline Hypothesis & Effect Of & Effect On & $\boldsymbol{\beta}$ & P-value & Result \\
\hline H1 & HPWS & JS & 0.42 & $* * *$ & Supported \\
\hline H2 & JS & ITQ & -0.39 & $* * *$ & Supported \\
\hline H3 & HPWS & PM & 0.56 & $* * *$ & Supported \\
\hline H4 & PM & ITQ & -0.28 & $* * *$ & Supported \\
\hline H5 & HPWS & ITQ & 0.014 & $*$ & Not Supported \\
\hline H6a & HPWS X GM & JS & 0.55 & $* * *$ & Supported \\
\hline H6b & HPWS X GM & PM & 0.68 & $* * *$ & Supported \\
\hline
\end{tabular}

Note: HPWS: high-performance work systems; JS: job satisfaction; PM: performance; ITQ: intention to quit; GM: gamification

*** denotes $\mathrm{p}<0.01 ;{ }^{*}$ denotes $\mathrm{p}>0.1$

Table 5. Structural Estimates

We examined the model's exploratory power by calculating the explained variance of the endogenous constructs. This method is in line with the objectives of PLS that aim to maximize the variance explained by the endogenous variable. $R^{2}$ values obtained were -0.732 for ITQ, 0.434 for JS, and 0.358 for PM - which are moderately strong (Chin, 1998). Next, we calculated 
the effect size of each predictor using Cohen $\mathrm{f}^{2}$ (Cohen, 1998). $\mathrm{f}^{2}$ is equal to the increase in $\mathrm{R}^{2}$ relative to the proportion of variance that remains unexplained in the endogenous latent variable (Dubey et al., 2019). Following the guidelines laid by Cohen (1998), we found that $\mathrm{f}^{2}$ for all the relationships was higher than 0.35 , which concludes that $\mathrm{f}^{2}$ is considerably large. As the last step, we calculated the model's capability to predict for which we calculated StoneGeisser's Q2 for all the endogenous variables. Peng and Lai (2012) stated that the model should consider having acceptable predictive relevance if the values are greater than zero. We found $\mathrm{Q}^{2}$ for JS, PM, and ITQ and found their values to be $0.657,0.592$, and 0.603 , respectively. The results of hypothesis testing can be seen in Table 5 .

\section{Discussion of Results}

The study offers exciting results in the context of the gig sector. The study provides strong insights into how to engage gig workers and control turnover in the sector. We drive our discussions on the basis of social exchange theory to explain how firms and employees work in tandem, weighing opportunities and rewards against threats and risks involved in tasks (Firth et al., 2004; Zito et al., 2018). Studies have examined the application of SET in various industries and used it to determine reasons behind employees staying or leaving the organization. Moreover, unlike the much-discussed employer-employee relationship with respect to social exchange theory, there lies a gap in the context of gig employee-employer relationship that is fundamentally different from the former. While reflecting upon the nuances and functions of the gig work arrangement, it is important to add another supporting theoretical lens to understand its functions better. We draw insights from SDT which helps in explaining the positive motivation that a gig worker experiences by doing gig work, which in turn accelerates work efficiency, boosts motivation and reduces dropout rate (Wagner et al., 2012; Frenkel et al., 2013). We discuss the theoretical and managerial contributions of the study in this section.

\subsection{Theoretical Implications}

The study uses supporting arguments drawn from SET and SDT in the context of understanding the motivations and intentions of gig workers, which is a unique contribution of the study. Results, therefore, broadly support underlying arguments drawn from social exchange theory. Our research confirms that gig workers who are highly satisfied and productive are less likely to quit the platform. $\mathrm{H} 2$ and $\mathrm{H} 4$ showed negative relationship between job performance and intentions to quit, and productivity and intentions to quit, respectively. Considering the coefficient of $\mathrm{H} 2$ and $\mathrm{H} 4$, we can conclude that while there exists a lower chance of gig workers exiting the online platform, it is essential to seek a way to further reduce the chances of exiting the system. First, the study supports that HPWS has a significant positive impact on job satisfaction and productivity of gig workers (H1). Although similar arguments have been made in literature (Gracia-Chas et al., 2016; Fabi et al., 2015), the contextual application in the gig space adds a new dimension. The autonomous and partially regulated work environment further supports the idea that gig employees face lesser burnouts and mental fatigue. The online engagement of the blue-collar gig workforce primarily driven by a higher level of creativity and mental ability gives the workforce the independence to choose work assignments complementing their competence (Lertxundi \& Landeta, 2011; Gkorezis et al., 2018). Additionally, freedom in work adds to their productivity. Second, against the backdrop of the existing negative relationship between HPWS and intentions to quit (Fabi et al., 2015), we posed a counter-intuitive argument (H5). Results confirm that there 
is no significant relationship between dependent and independent variables. Heffernan and Dundon (2016) also presented a similar non-significant relationship. Instead of the work and the working attributes of a gig worker, the study adds a new dimension. In the context of gig platforms, interaction between employees and employers is minor as compared to that in fulltime employment. Thus, high-performance work systems that involve selection, training, performance appraisal, and compensation do not apply to a large extent in the gig economy (Jabagi et al., 2019). For example, the selection process is like an agreement based on resource valuations discussed between employer and employee. Thus, the relationship between the HPWS and intention to quit or intentions to switch is grey in this case (Stewart \& Stanford, 2017).

The third theoretical contribution is the role of gamification as moderator which motivates gig employees to a higher degree (H6a and H6b). This phenomenon is elucidated mainly by the principles of SDT that help explain intrinsic and extrinsic motivations of the gig worker. As gig workers do not operate in a regulated and monitored physical and administrative environment, the degree of autonomy at times has a counterproductive effect, resulting in late delivery or substandard quality (Mekler et al., 2017; Brawley, 2017). Gamification shows a positive and significant impact on the relationship between HPWS and job satisfaction, as well as between HPWS and productivity (H6a and H6b). Just as firms use multiple activities under HPWS to ensure high employee efficiency, the same is the case of a gig worker. The use of game elements in critical HR functions (like compensations, bonuses, training and development, etc.) helps in reinforcing engagement with the online platform and the work involved. Results also support the conceptual model proposed by Xi and Hamari (2019) on gamified work engagements.

\subsection{Practical Implications}

The study makes some significant contributions to existing approaches and ways of engaging gig workers on online platforms. The unregulated character of the gig sector makes it explicitly hard for both organizations and employees to have a sustainable relationship with each other. The organizations are confronted with the challenges of building capabilities to adapt to this new work idea. Employees find it correspondingly complex to manage challenges of lack of job structure and financial anxiety, leading to decreased motivation. Hence, managing employees in alternative work structures such as the gig economy requires new strategies. The results established that introducing game-based engagements would boost the motivation of gig employees, resulting in higher productivity and job satisfaction. These insights can be applied for both white and blue-collar gig workers (Huang et al., 2020).

This becomes more critical when, in the future, we will witness a growth of gig work. Furthermore, in uncertain and challenging times like the one seen during the current global pandemic of COVID 19, gig work is expected to gain more relevance and hence the existing HRM practices are likely to gain more attention and expected to evolve specific to the dynamic requirements of new work structures. In proposing the use of gamified rewards by gig platforms in the form of lucrative deals/offers, the current study offers practitioners with a tangible, innovative strategy that can motivate gig employees and reduce attrition. Our results would also appeal to firms in the process of moving some of their regular processes to gig platforms. The study will help them with a requisite design for gig employee engagement to achieve the sought after goals (Kumar, 2013; Burtch et al., 2018). Scouting for and retaining productive and talented white-collar workers could be bolstered by game mechanics. 
Organizations can link point-driven leader boards, trophies, and accolades to job-related performance metrics, which will further drive commitment and help classify and retain productive and talented white-collar workers. The classification through this retention mechanism will help firms understand the expectations and working styles of workers leading to more effective task allotment.

Use of gamification can yield expected results if designed, keeping in mind the participant types and motivations that drive the players. Organizations can analyse and aim to align specific gamification mechanics like rewards and challenges with a particular employee type for desired outcomes. The playfulness aspect associated with gamification can help organisations build a positive work environment for gig workers, thus reducing work-related stress leading to greater productivity.

Our results will also aid gig workers by helping them resolve administrative issues and cope with work stress and getting rewards over and above their compensation levels; findings could also provide inputs to strengthen brand loyalty (Hsu \& Chen, 2018). A loyal gig employee could lead to an equally minded workforce, and gamification could then be used in the referral scheme of the website.

\subsection{Future Scope of work}

The study considers only white-collar gig workers enrolled with online platforms, while the population of blue-collar gig workers is large, a comparable study needs to be conducted to explore the differences. While the study did explore online engagement and why workers quit , the study did not test for all scenarios that could make workers quit. The study can be further extended to understand how gig work is managed across different work disciplines and cultures. Moreover, studies could use simulations or experiment-based approaches to determine which game artifacts lead to a higher engagement rate. Following the guidelines of Morschheuset et al. (2019) and Feng et al. (2018), we propose to design websites where different game artifacts can be used to determine the reaction and response of gig workers with similar tasks. Additionally, the tasks can also be changed in terms of its rigor, time and monetary rewards to answer three key questions: when, how and which game artifacts would be useful for controlling/reducing the chances of quitting. A mixed-method approach to understanding the reasons for gig workers quitting needs to be conducted, followed by analysis of drivers using longitudinal data. The study calls for an examination of circumstances under which gig workers would be more likely to continue, and that of those under which gig workers would be more likely to quit. Similarly, studies could examine ways to improve gig worker retention by exploring this area using a grounded theory approach and a case-based approach as suggested by Jabagi et al. (2019). Future studies can be developed using Ketokivi and Choi(2014) guidelines to understand the phenomenon of the functioning of game elements in HPWS. There appears to be a need for an appropriate engagement plan that could be customized and flexible so that they can be revised as and when required in different situations. An extension of this study could involve further exploration in the fields of Psychology, Human Resources and Law with respect to gig work challenges.

\section{Conclusion}

The study explores a significant phenomenon within the emerging sector of gig economyintentions of workers to quit gig work on online platforms. The study formulates hypotheses using social exchange theory and self-determination theory and proposed that the dark side 
of gig work can be resolved by working on ways to reduce the rate of dropouts of gig workers using gamification. Results confirm that high-performance work systems help gig workers achieve a higher degree of productivity and satisfaction. While these attributes are essential, the sector still witnesses significant dropouts. Results suggest that by introducing gamified online platforms, we can improve work productivity, job satisfaction, and engagement of gig workers; this, in turn, could improve gig workforce retention. The nature and complexity of work performed by white collared gig workers makes their availability low on such platforms and therefore gig platforms often empanel them in order to draw more benefits from their services. The study offers mechanisms that would help online platforms retain the gig workforce.

\section{References}

Abraham, K. G., Haltiwanger, J. C., Sandusky, K., \& Spletzer, J. R. (2018). Measuring the gig economy: Current knowledge and open issues (No. w24950). National Bureau of Economic Research. Cambridge, MA.

Ang, S. H., Bartram, T., McNeil, N., Leggat, S. G., \& Stanton, P. (2013). The effects of highperformance work systems on hospital employees' work attitudes and intention to leave: a multi-level and occupational group analysis. The International Journal of Human Resource Management, 24(16), 3086-3114.

Anwar, M. A., \& Graham, M. (2020). Between a rock and a hard place: Freedom, flexibility, precarity and vulnerability in the gig economy in Africa. Competition $\mathcal{E}$ Change. DOI: https://doi.org/10.1177/1024529420914473

Armstrong, J. S., \& Overton, T. S. (1977). Estimating nonresponse bias in mail surveys. Journal of Marketing Research, 14(3), 396-402.

Aryee, S., Walumbwa, F. O., Seidu, E. Y., \& Otaye, L. E. (2012). Impact of high-performance work systems on individual-and branch-level performance: test of a multilevel model of intermediate linkages. Journal of Applied Psychology, 97(2), 287-300.

Aryee, S., Walumbwa, F. O., Seidu, E. Y., \& Otaye, L. E. (2016). Developing and leveraging human capital resource to promote service quality: Testing a theory of performance. Journal of Management, 42(2), 480-499.

Behl, A. (2020). Antecedents to firm performance and competitiveness using the lens of big data analytics: a cross-cultural study. Management Decision.

Behl, A., \& Dutta, P. (2020). Engaging donors on crowdfunding platform in Disaster Relief Operations (DRO) using gamification: A Civic Voluntary Model (CVM) approach. International Journal of Information Management, 54, 102140. DOI: https://doi.org/10.1016/j.jijinfomgt.2020.102140

Behravesh, E., Tanova, C., \& Abubakar, A. M. (2020). Do high-performance work systems always help to retain employees or is there a dark side? The Service Industries Journal, 40(11-12), 825-845.

Bera, A. K., \&Jarque, C. M. (1981). Efficient tests for normality, homoscedasticity and serial independence of regression residuals: Monte Carlo evidence. Economics letters, 7(4), 313318. 
Berger, T., Frey, C. B., Levin, G., \&Danda, S. R. (2019). Uber happy? Work and well-being in the 'gig economy'. Economic Policy, 34(99), 429-477.

Biron, M., \& Boon, C. (2013). Performance and turnover intentions: A social exchange perspective. Journal of Managerial Psychology, 28(5), 511-531.

Blanchard, C., Baker, A., Perreault, D., Mask, L., \& Tremblay, M. (2019). The importance of keeping employees satisfied. Journal of Health Organization and Management, 34(1), 23-39.

Blau, P.M. (1964), Social Exchange Theory. New York: John Wiley \& Sons.

Boon, C., Den Hartog, D. N., Boselie, P., \& Paauwe, J. (2011). The relationship between perceptions of HR practices and employee outcomes: examining the role of personorganisation and person-job fit. The International Journal of Human Resource Management, 22(01), 138-162.

Bott, J. P., Svyantek, D. J., Goodman, S. A., \& Bernal, D. S. (2003). Expanding the performance domain: who says nice guys finish last? International Journal of Organizational Analysis, 11(2), 137-152.

Brawley, A. M. (2017). The big, gig picture: We can't assume the same constructs matter. Industrial and Organizational Psychology, 10(4), 687-696.

Brown, T. (2009). The gig economy. The Daily Beast. Accessed on 12 March, 2020 at https:/www.thedailybeast.com/articles/2009/01/12/the-gigeconomy.html.

Burtch, G., Carnahan, S., \& Greenwood, B. N. (2018). Can you gig it? An empirical examination of the gig economy and entrepreneurial activity. Management Science, 64(12), 5497-5520.

Cafferkey, K., \&Dundon, T. (2015). Explaining the black box: HPWS and organisational climate. Personnel Review, 44(5), 666-688.

Cardador, M. T., Northcraft, G. B., \&Whicker, J. (2017). A theory of work gamification: Something old, something new, something borrowed, something cool?. Human Resource Management Review, 27(2), 353-365.

Carr, C. T., Hall, R. D., Mason, A. J., \& Varney, E. J. (2017). Cueing employability in the gig economy: Effects of task-relevant and task-irrelevant information on Fiverr. Management Communication Quarterly, 31(3), 409-428.

Çeker, E., \& Özdaml, F. (2017). What" Gamification" Is and What It's Not. European Journal of Contemporary Education, 6(2), 221-228.

Chang, P. C., \& Chen, S. J. (2011). Crossing the level of employee's performance: HPWS, affective commitment, human capital, and employee job performance in professional service organizations. The International Journal of Human Resource Management, 22(04), 883-901.

Chin, W. W. (1998). The partial least squares approach to structural equation modeling. Modern Methods for Business Research, 295(2), 295-336.

Chou, Y. K. (2019). Actionable gamification: Beyond points, badges, and leaderboards. Packt Publishing Ltd.

Cohen, J. E. (1988). Statistical Power Analysis for the Behavioral Sciences. Hillsdale, NJ: Lawrence Erlbaum Associates, Inc. 
Connelly, C. E., Fieseler, C., Černe, M., Giessner, S. R., \& Wong, S. I. (2020). Working in the digitized economy: HRM theory \& practice. Human Resource Management Review, 100762.

Cook, K. S., Cheshire, C., Rice, E. R., \& Nakagawa, S. (2013). Social exchange theory. In Handbook of social psychology. Springer, Dordrecht.

Cropanzano, R., \& Mitchell, M. S. (2005). Social exchange theory: An interdisciplinary review. Journal of Management, 31(6), 874-900.

Cropanzano, R., Anthony, E. L., Daniels, S. R., \& Hall, A. V. (2017). Social exchange theory: A critical review with theoretical remedies. Academy of Management Annals, 11(1), 479-516.

Dale, S. (2014). Gamification: Making work fun or making fun of work? Business information review, 31(2), 82-90.

Davidson, R., \& MacKinnon, J. G. (1993). Estimation and inference in econometrics. OUP Catalogue, London, UK.

Deci, E. L., \& Ryan, R. M. (2002). Overview of self-determination theory: An organismic dialectical perspective. Handbook of self-determination research, 3-33.

Deci, E. L., \& Ryan, R. M. (2008). Self-determination theory: A macrotheory of human motivation, development, and health. Canadian psychology/Psychologie canadienne, 49(3), 182.

Deterding, S. (2019). Gamification in management: Between choice architecture and humanistic design. Journal of Management Inquiry, 28(2), 131-136.

Dubey, R., Gunasekaran, A., Childe, S. J., Bryde, D. J., Giannakis, M., Foropon, C., ... \& Hazen, B. T. (2020). Big data analytics and artificial intelligence pathway to operational performance under the effects of entrepreneurial orientation and environmental dynamism: A study of manufacturing organisations. International Journal of Production Economics, 107599. DOI: https://doi.org/10.1016/j.ijpe.2019.107599

Gillespie, P. (2017), "Intuit: gig economy is $34 \%$ of US workforce", available at: http://money.cnn.com/2017/05/24/news/economy/gig-economy-intuit/index.html (accessed May 10, 2020).

Emerson, R. M. (1976). Social exchange theory. Annual Review of Sociology, 2(1), 335-362.

Fabi, B., Lacoursière, R., \& Raymond, L. (2015). Impact of high-performance work systems on job satisfaction, organizational commitment, and intention to quit in Canadian organizations. International Journal of Manpower, 36(5), 772-790.

Faisal, A. L. F., Sucahyo, Y. G., Ruldeviyani, Y., \& Gandhi, A. (2019, July). Discovering Indonesian Digital Workers in Online Gig Economy Platforms. In 2019 International Conference on Information and Communications Technology (ICOIACT), 554-559. IEEE.

Feng, Y., Ye, H. J., Yu, Y., Yang, C., \& Cui, T. (2018). Gamification artifacts and crowdsourcing participation: Examining the mediating role of intrinsic motivations. Computers in Human Behavior, 81, 124-136.

Firth, L., Mellor, D. J., Moore, K. A., \&Loquet, C. (2004). How can managers reduce employee intention to quit?. Journal of Managerial Psychology, 19(2), 170-187. 
Fisher, S. L., \& Cassady, E. A. (2019). Use of Relational eHRM Tools in Gig Worker Platforms. In HRM 4.0 For Human-Centered Organizations. Emerald Publishing Limited, UK.

Fornell, C., \& Larcker, D. F. (1981). Evaluating structural equation models with unobservable variables and measurement error. Journal of Marketing Research, 18(1), 39-50.

Frenkel, S., Sanders, K., \& Bednall, T. (2013). Employee perceptions of management relations as influences on job satisfaction and quit intentions. Asia Pacific Journal of Management, 30(1), 7-29.

Friedman, G. (2014). Workers without employers: shadow corporations and the rise of the gig economy. Review of Keynesian Economics, 2(2), 171-188.

Fugate, M., Prussia, G. E., \& Kinicki, A. J. (2012). Managing employee withdrawal during organizational change: The role of threat appraisal. Journal of Management, 38(3), 890-914.

Gagné, M., \& Deci, E. L. (2005). Self-determination theory and work motivation. Journal of Organizational Behavior, 26(4), 331-362.

Gannon, J. M., Roper, A., \& Doherty, L. (2015). Strategic human resource management: Insights from the international hotel industry. International Journal of Hospitality Management, 47, 65-75.

Gandini, A. (2019). Labour process theory and the gig economy. Human Relations, 72(6), 10391056.

Gandhi, A., Hidayanto, A. N., Sucahyo, Y. G., \& Ruldeviyani, Y. (2018, October). Exploring people's intention to become platform-based gig workers: An empirical qualitative study. In 2018 International Conference on Information Technology Systems and Innovation (ICITSI), 266-271, IEEE.

García-Chas, R., Neira-Fontela, E., \& Castro-Casal, C. (2014). High-performance work system and intention to leave: a mediation model. The International Journal of Human Resource Management, 25(3), 367-389.

García-Chas, R., Neira-Fontela, E., \& Varela-Neira, C. (2016). High-performance work systems and job satisfaction: a multilevel model. Journal of Managerial Psychology, 31(2), 451-466.

Garmendia, A., Elorza, U., \& Aritzeta, A. (2019, July). HPWS, Job Satisfaction and Productivity: A Longitudinal Study of a Spanish Retail Company. In Academy of Management Proceedings, 2019(1), 10673-10675.

Gefen, D., \& Straub, D. (2005). A practical guide to factorial validity using PLS-Graph: Tutorial and annotated example. Communications of the Association for Information systems, 16(1), 91-109.

Gkorezis, P., Georgiou, L., \& Theodorou, M. (2018). High-performance work practices and nurses' intention to leave: The mediating role of organizational cynicism and the moderating role of human resource management-related educational background. The International Journal of Human Resource Management, 29(3), 465-484.

Gleim, M. R., Johnson, C. M., \& Lawson, S. J. (2019). Sharers and sellers: A multi-group examination of gig economy workers' perceptions. Journal of Business Research, 98, 142152. 
Guest, D. E. (2017). Human resource management and employee well-being: Towards a new analytic framework. Human Resource Management Journal, 27(1), 22-38.

Guide Jr, V. D. R., \& Ketokivi, M. (2015). Notes from the Editors: Redefining some methodological criteria for the journal. Journal of Operations Management, 37(1), v-viii.

Hair Jr, J. F., Sarstedt, M., Hopkins, L., \& Kuppelwieser, V. G. (2014). Partial least squares structural equation modeling (PLS-SEM). European Business Review, 26(2), 06-121.

Haivas, S., Hofmans, J., \& Pepermans, R. (2013). Volunteer engagement and intention to quit from a self-determination theory perspective. Journal of Applied Social Psychology, 43(9), 1869-1880.

Hamari, J., Koivisto, J., \& Sarsa, H. (2014, January). Does gamification work?--a literature review of empirical studies on gamification. In 2014 47th Hawaii international conference on system sciences (pp. 3025-3034). IEEE.

Hasija, S., Padmanabhan, V., \& Rampal, P(2020, June). Will the Pandemic Push Knowledge Work into the Gig Economy? Harvard Business Review. Accessed on $8^{\text {th }}$ October 2020 at https://hbr.org/2020/06/will-the-pandemic-push-knowledge-work-into-the-gigeconomy

Healy, J., Nicholson, D., \& Pekarek, A. (2017). Should we take the gig economy seriously?. Labour \& Industry: a journal of the social and economic relations of work, 27(3), 232-248.

Heeks, R. (2017). Decent work and the digital gig economy: a developing country perspective on employment impacts and standards in online outsourcing, crowdwork, etc. Development Informatics Working Paper, (71). Available at: http://hummedia.manchester.ac.uk/institutes/gdi/ publications/workingpapers/di/ di_wp71.pdf (accessed 20 March 2020).

Heffernan, M., \& Dundon, T. (2016). Cross-level effects of high-performance work systems (HPWS) and employee well-being: the mediating effect of organisational justice. Human Resource Management Journal, 26(2), 211-231.

Henseler, J., Ringle, C. M., \& Sarstedt, M. (2015). A new criterion for assessing discriminant validity in variance-based structural equation modeling. Journal of the Academy of Marketing Science, 43(1), 115-135.

Hobfoll, S. E., Shirom, A., \& Golembiewski, R. (2000). Conservation of resources theory. appears in Handbook of Organizational Behavior, RT Golembiewski (ed.), Marcel Dekker, New York, 57-80.

Holt, T. J., \& Kennedy, J. P. (2019). Technology's Influence on White-Collar Offending, Reporting, and Investigation. The Handbook of White-Collar Crime, 449-468.

Homans, C. G. (1967). Fundamental social processes. In Sociology. ed. N. J. Smdser. New York: Wiley

Homans, G. C. (1961). Social behavior: Its elementary forms (Revised ed.). Harcourt Brace Jovanovich. 
Hsu, C. L., \& Chen, M. C. (2018). How gamification marketing activities motivate desirable consumer behaviors: Focusing on the role of brand love. Computers in Human Behavior, 88, 121-133.

Huang, N., Burtch, G., Hong, Y., \&Pavlou, P. A. (2020). Unemployment and Worker Participation in the Gig Economy: Evidence from An Online Labor Market. Information Systems Research. DOI: https://doi.org/10.1287/isre.2019.0896

Huotari, K., \& Hamari, J. (2017). A definition for gamification: anchoring gamification in the service marketing literature. Electronic Markets, 27(1), 21-31.

Huselid, M. A. (1995). The impact of human resource management practices on turnover, productivity, and corporate financial performance. Academy of Management Journal, 38(3), 635-672.

Jabagi, N., Croteau, A. M., Audebrand, L. K., \& Marsan, J. (2019). Gig-workers' motivation: thinking beyond carrots and sticks. Journal of Managerial Psychology, 34(4), 192-213.

Jiang, K., Lepak, D. P., Hu, J., \& Baer, J. C. (2012). How does human resource management influence organizational outcomes? A meta-analytic investigation of mediating mechanisms. Academy of Management Journal, 55(6), 1264-1294.

Jyoti, J., \& Rani, A. (2019). Role of burnout and mentoring between high performance work system and intention to leave: Moderated mediation model. Journal of Business Research, 98, 166-176.

Kapp, K. M. (2012). The gamification of learning and instruction: game-based methods and strategies for training and education. John Wiley \& Sons.

Kässi, O., \& Lehdonvirta, V. (2018). Online labour index: Measuring the online gig economy for policy and research. Technological Forecasting and Social Change, 137, 241-248.

Kehoe, R. R., \& Wright, P. M. (2013). The impact of high-performance human resource practices on employees' attitudes and behaviors. Journal of Management, 39(2), 366-391.

Keith, M. G., Harms, P., \& Tay, L. (2019). Mechanical Turk and the gig economy: exploring differences between gig workers. Journal of Managerial Psychology, 34(4), 286-306.

Ketokivi, M., \& Choi, T. (2014). Renaissance of case research as a scientific method. Journal of Operations Management, 32(5), 232-240.

Ketokivi, M., \& Schroeder, R. (2004). Manufacturing practices, strategic fit and performance. International Journal of Operations \& Production Management, 24(2), 171-191.

Khan, A., Boroomand, F., Webster, J., \& Minocher, X. (2020). From Elements to Structures: An Agenda for Organisational Gamification. European Journal of Information Systems, 1-20.

Kilhoffer, Z., Lenaerts, K., \& Beblavý, M. (2017), “The platform economy and industrial relations applying the old framework to the new reality", Research Report No. 2017/12, European Centre for Political Studies (CEPS), Brussels.

Kock, N. (2015). Common method bias in PLS-SEM: A full collinearity assessment approach. International Journal of e-Collaboration (ijec), 11(4), 1-10.

Koivisto, J., \& Hamari, J. (2014). Demographic differences in perceived benefits from gamification. Computers in Human Behavior, 35, 179-188. 
Kuhn, K. M., \& Galloway, T. L. (2019). Expanding perspectives on gig work and gig workers. Journal of Managerial Psychology, 34(4), 186-191.

Kumar, J. (2013, July). Gamification at work: Designing engaging business software. In International conference of design, user experience, and usability. Springer, Berlin, Heidelberg.

Kundu, S. C., \& Gahlawat, N. (2016). High performance work systems and employees' intention to leave. Management Research Review, 39(12), 1587-1615.

Kurin, J. (2016). A Third Way for Applying US Labor Laws to the Online Gig Economy: Using the Franchise Business Model to Regulate Gig Workers. Journal of Business \& Technology Law, 12(2), 193.

Landers, R. N., Bauer, K. N., Callan, R. C., \& Armstrong, M. B. (2015). Psychological theory and the gamification of learning. In Gamification in education and business (pp. 165186). Springer, Cham.

Lee, C. H., \& Bruvold, N. T. (2003). Creating value for employees: investment in employee development. The International Journal of Human Resource Management, 14(6), 981-1000.

Lee, H. C. B., Ba, S., Li, X., \& Stallaert, J. (2018). Salience bias in crowdsourcing contests. Information Systems Research, 29(2), 401-418.

Lehdonvirta, V. (2018). Flexibility in the gig economy: managing time on three online piecework platforms. New Technology, Work and Employment, 33(1), 13-29.

Lertxundi, A., \& Landeta, J. (2011). The moderating effect of cultural context in the relation between HPWS and performance: An exploratory study in Spanish multinational companies. The International Journal of Human Resource Management, 22(18), 3949-3967.

Lindell, M. K., \& Whitney, D. J. (2001). Accounting for common method variance in crosssectional research designs. Journal of Applied Psychology, 86(1), 114.

Liu, W., He, C., Jiang, Y., Ji, R., \&Zhai, X. (2020). Effect of Gig Workers' Psychological Contract Fulfillment on Their Task Performance in a Sharing Economy-A Perspective from the Mediation of Organizational Identification and the Moderation of Length of Service. International Journal of Environmental Research and Public Health, 17(7), 2208.

Locke, E. A. (1976). The nature and causes of job satisfaction. Handbook of industrial and organizational psychology. Rand McNally, Chicago, IL

Longley, R. (2020). Gig Economy: Definition and Pros and Cons. ThoughtCo, Accessed on Feb. 11, 2020, Available at thoughtco.com/gig-economy-4588490.

McFeely, S., \& Pendell, R. (2018). What Workplace Leaders Can Learn from the Real Gig Economy. Gallup Workplace.

Manyika, J., Lund, S., Bughin, J., Robinson, K., Mischke, J., \& Mahajan, D. (2016). Independent work: Choice, necessity, and the gig economy. McKinsey Global Institute, 2016, 1-16.

Masood, A., Feng, Y., Rasheed, M. I., Ali, A., \& Gong, M. (2020). Smartphone-based social networking sites and intention to quit self-regulatory perspective. Behaviour $\mathcal{E}$ Information Technology, 1-17. DOI: https://doi.org/10.1080/0144929X.2020.1740787 
Meijerink, J., \& Keegan, A. (2019). Conceptualizing human resource management in the gig economy. Journal of Managerial Psychology, 34(4), 214-23.

Mekler, E. D., Brühlmann, F., Tuch, A. N., \& Opwis, K. (2017). Towards understanding the effects of individual gamification elements on intrinsic motivation and performance. Computers in Human Behavior, 71, 525-534.

Michaelis, B., Wagner, J. D., \& Schweizer, L. (2015). Knowledge as a key in the relationship between high-performance work systems and workforce productivity. Journal of Business Research, 68(5), 1035-1044.

Morschheuser, B., Hamari, J., \& Maedche, A. (2019). Cooperation or competition-When do people contribute more? A field experiment on gamification of crowdsourcing. International Journal of Human-Computer Studies, 127, 7-24.

Nye, F. I. (1978). Is choice and exchange theory the key? Journal of Marriage and Family, 40(2), 219-233.

Ornek, O. K., Weinmann, T., Waibel, J., \& Radon, K. (2020). Precarious employment and migrant workers' mental health: a protocol for a systematic review of observational studies. Systematic Reviews, 9(1), 1-6.

Peng, D. X., \& Lai, F. (2012). Using partial least squares in operations management research: A practical guideline and summary of past research. Journal of Operations Management, 30(6), 467-480.

Petriglieri, G., Ashford, S. J., \& Wrzesniewski, A. (2019). Agony and ecstasy in the gig economy: Cultivating holding environments for precarious and personalized work identities. Administrative Science Quarterly, 64(1), 124-170.

Petriglieri, G., Ashford, S., \& Wrzesniewski, A. (2018). Thriving in the gig economy. HBR'S 10 MUST, 109.

Pichault, F., \& McKeown, T. (2019). Autonomy at work in the gig economy: analysing work status, work content and working conditions of independent professionals. New Technology, Work and Employment, 34(1), 59-72.

Poon, T. S. C. (2019). Independent workers: Growth trends, categories, and employee relations implications in the emerging gig economy. Employee Responsibilities and Rights Journal, 31(1), 63-69.

Prabowo, R., Sucahyo, Y. G., Gandhi, A., \&Ruldeviyani, Y. (2019, October). Does Gamification Motivate Gig Workers? A Critical Issue in Ride-Sharing Industries. In 2019 International Conference on Advanced Computer Science and information Systems (ICACSIS) (pp. 343-348). IEEE.

Quinn, R., \& Staines, G. (1979). The 1977 Quality of Employment Survey: Descriptive Statistics, with Comparison Data from the 1969-70 and the 1972-73 Surveys, Survey Research Center, Institute for Social Research, University of Michigan Press, Ann Arbor, MI.

Redondo, R., Sparrow, P., \& Hernández-Lechuga, G. (2019). The effect of protean careers on talent retention: examining the relationship between protean career orientation, organizational commitment, job satisfaction and intention to quit for talented 
workers. The International Journal of Human Resource Management, 1-24. DOI: https://doi.org/10.1080/09585192.2019.1579247

Robson, K., Plangger, K., Kietzmann, J. H., McCarthy, I., \& Pitt, L. (2015). Is it all a game? Understanding the principles of gamification. Business Horizons, 58(4), 411-420.

Rockmann, K., Jacob, M. R., \& George, E. (2018). The Drive to Drive: Understanding Gig Work by Understanding the Gig Worker. Academy of Management Global Proceedings. Accessed on $6^{\text {th }}$ October 2020 at https://journals.aom.org/doi/abs/10.5465/amgblproc.surrey. 2018.0088.abs

Rosenthal, R., \& Rosnow, R. L. (2008). Essentials of behavioral research: Methods and data analysis. McGraw-Hill, Boston.

Ruhi, U. (2015). Level up your strategy: Towards a descriptive framework for meaningful enterprise gamification. Technology Innovation Management Review, 5(8), 5-16.

Seaborn, K., \& Fels, D. I. (2015). Gamification in theory and action: A survey. International Journal of human-computer studies, 74, 14-31.

Sailer, M., Hense, J. U., Mayr, S. K., \& Mandl, H. (2017). How gamification motivates: An experimental study of the effects of specific game design elements on psychological need satisfaction. Computers in Human Behavior, 69, 371-380.

Scheiber, N. (2017). How Uber uses psychological tricks to push its drivers' buttons. The New York Times, 2. Available at: https://www.nytimes.com/interactive/2017/04/02/ technology/100000005019770.app.html?nytapp=iphone\&_r=1 (accessed 2 April 2020).

Schwellnus, C., Geva, A., Pak, M., \& Veiel, R. (2019). Gig economy platforms: Boon or Bane?.OECD Economics Department Working Papers, No. 1550, OECD Publishing, Paris, https://doi.org/10.1787/fdb0570b-en.

Sepehr, S., \& Head, M. (2013, October). Competition as an element of gamification for learning: an exploratory longitudinal investigation. In Proceedings of the First International Conference on Gameful Design, Research, and Applications, 2-9.

Shatz, I. (2015). Using gamification and gaming in order to promote risk taking in the language learning process. In Proceedings of the 13th Annual MEITAL National Conference. Haifa, Israel: Technion, 227-32.

Shi, L., \& Cristea, A. I. (2016, June). Motivational gamification strategies rooted in selfdetermination theory for social adaptive e-learning. In International Conference on Intelligent Tutoring Systems (pp. 294-300). Springer, Cham.

Sun, L. Y., Aryee, S., \& Law, K. S. (2007). High-performance human resource practices, citizenship behavior, and organizational performance: A relational perspective. Academy of Management Journal, 50(3), 558-577.

Stanford, J. (2017). The resurgence of gig work: Historical and theoretical perspectives. The Economic and Labour Relations Review, 28(3), 382-401.

Stewart, A., \& Stanford, J. (2017). Regulating work in the gig economy: What are the options? The Economic and Labour Relations Review, 28(3), 420-437. 
Swacha, J., \& Muszyńska, K. (2016, November). Design patterns for gamification of work. In Proceedings of the Fourth International Conference on Technological Ecosystems for Enhancing Multiculturality, 763-769.

Tenenhaus, M., Vinzi, V. E., Chatelin, Y. M., \& Lauro, C. (2005). PLS path modeling. Computational Statistics \& Data Analysis, 48(1), 159-205.

Tett, R. P., \& Meyer, J. P. (1993). Job satisfaction, organizational commitment, turnover intention, and turnover: path analyses based on meta-analytic findings. Personnel Psychology, 46(2), 259-293.

Tirapani, A. N., \& Willmott, H. C. (2020). Theorizing Radical Conflict: Employment Relations in the Gig Economy. In Academy of Management Proceedings (Vol. 2020, No. 1, p. 18975). Briarcliff Manor, NY 10510: Academy of Management.

Treuren, G. J. (2019). Employee embeddedness as a moderator of the relationship between work and family conflict and leaving intention. The International Journal of Human Resource Management, 30(17), 2504-2524.

Van Rhee, H., \& Dul, J. (2018, July). Filling the black box of HR: Unraveling the AMO model and elevating it to the organizational level. In Academy of Management Proceedings, 2018, (1), 13840-45.

van Roy, R., \& Zaman, B. (2019). Unravelling the ambivalent motivational power of gamification: A basic psychological needs perspective. International Journal of HumanComputer Studies, 127, 38-50.

Wagner, J. D., Michaelis, B., \& Schweizer, L. (2012, July). Knowledge as a Key Factor in the Relationship between HPWS and Workforce Productivity. In Academy of Management Proceedings (Vol. 2012, No. 1, p. 11647). Briarcliff Manor, NY 10510: Academy of Management.

Weber, J., Azad, M., Riggs, W., \& Cherry, C. R. (2018). The convergence of smartphone apps, gamification and competition to increase cycling. Transportation research part F: traffic psychology and behaviour, 56, 333-343.

Werbach, K. (2014). (Re) Defining Gamification: A Process Approach. In Persuasive Technology (pp. 266-272). Springer International Publishers

Wiener, M., Cram, W. A., \& Benlian, A. (2020). Technology-Mediated Control Legitimacy in the Gig Economy: Conceptualization and Nomological Network. In Information Systems Outsourcing (pp. 387-410). Springer, Cham.

Williams, L. J., \& Anderson, S. E. (1991). Job satisfaction and organizational commitment as predictors of organizational citizenship and in-role behaviors. Journal of Management, 17(3), 601-617.

Wood, A. J., Graham, M., Lehdonvirta, V., \& Hjorth, I. (2019). Networked but commodified: The (dis) embeddedness of digital labour in the gig economy. Sociology, 53(5), 931-950.

Wu, N., Hoque, K., Bacon, N., \& Bou Llusar, J. C. (2015). High-performance work systems and workplace performance in small, medium-sized and large firms. Human Resource Management Journal, 25(4), 408-423. 
Wu, Y., Li, C., \& Khoo, S. (2016). Predicting future volunteering intentions through a selfdetermination theory perspective. VOLUNTAS: International Journal of Voluntary and Nonprofit Organizations, 27(3), 1266-1279.

Xi, N., \&Hamari, J. (2019). Does gamification satisfy needs? A study on the relationship between gamification features and intrinsic need satisfaction. International Journal of Information Management, 46, 210-221.

Ye, H. J., \& Kankanhalli, A. (2017). Solvers' participation in crowdsourcing platforms: Examining the impacts of trust, and benefit and cost factors. The Journal of Strategic Information Systems, 26(2), 101-117

Zhang, M., Zhu, C. J., Dowling, P. J., \& Bartram, T. (2013). Exploring the effects of highperformance work systems (HPWS) on the work-related well-being of Chinese hospital employees. The International Journal of Human Resource Management, 24(16), 3196-3212.

Zito, M., Emanuel, F., Molino, M., Cortese, C. G., Ghislieri, C., \& Colombo, L. (2018). Turnover intentions in a call center: The role of emotional dissonance, job resources, and job satisfaction. PloS one, 13(2), e0192126.

Zuckerman, M., Porac, J., Lathin, D., \& Deci, E. L. (1978). On the importance of selfdetermination for intrinsically motivated behavior. Personality and social psychology bulletin, 4(3), 443-446.

\section{Appendix A}

List of Crowdsourcing Platforms

\begin{tabular}{|l|l|l|l|}
\hline 1. & Kickstarter & 18. & HackerOne \\
\hline 2. & GoFundMe & 19. & Band of Hands \\
\hline 3. & Indiegogo & 20. & Gigwalk \\
\hline 4. & Patreon & 21. & Thumbtack \\
\hline 5. & RocketHub & 22. & Guru \\
\hline 6. & Ulule & 23. & FlexJobs \\
\hline 7. & Designhill & 24. & Freelancer \\
\hline 8. & uTest & 25. & Bellhops \\
\hline 9. & Mechanical Turk & 26. & Handy \\
\hline 10. & Trendwatching & 27. & HelloTech \\
\hline 11. & Quri & 28. & Hubstaff Talent \\
\hline 12. & Catalant & 29. & Moonlighting \\
\hline 13. & Turning Art & 30. & PeoplePerHour \\
\hline 14. & Wonolo & 31. & Snagajob \\
\hline 15. & Law Trades & 32. & Spare5 \\
\hline 16. & UpCounsel & 33. & IFreelance \\
\hline 17. & Toptal & 34. & Aquent \\
\hline
\end{tabular}


Copyright: (C) 2021 authors. This is an open-access article distributed under the terms of the Creative Commons Attribution-NonCommercial 3.0 Australia License, which permits noncommercial use, distribution, and reproduction in any medium, provided the original author and AJIS are credited.

doi: https://doi.org/10.3127/ajis.v25i0.2979

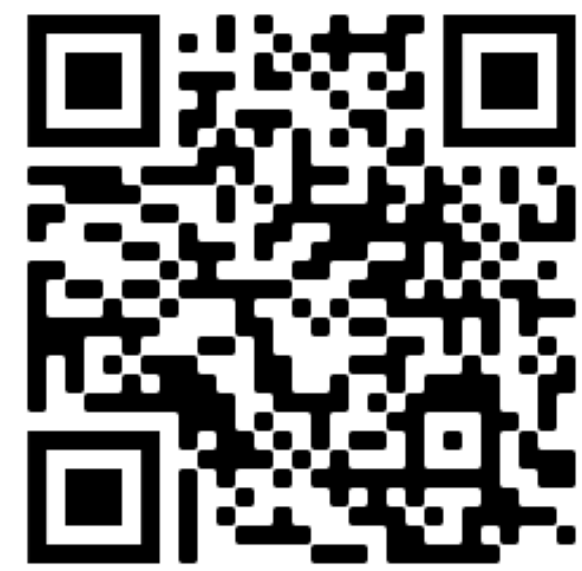

